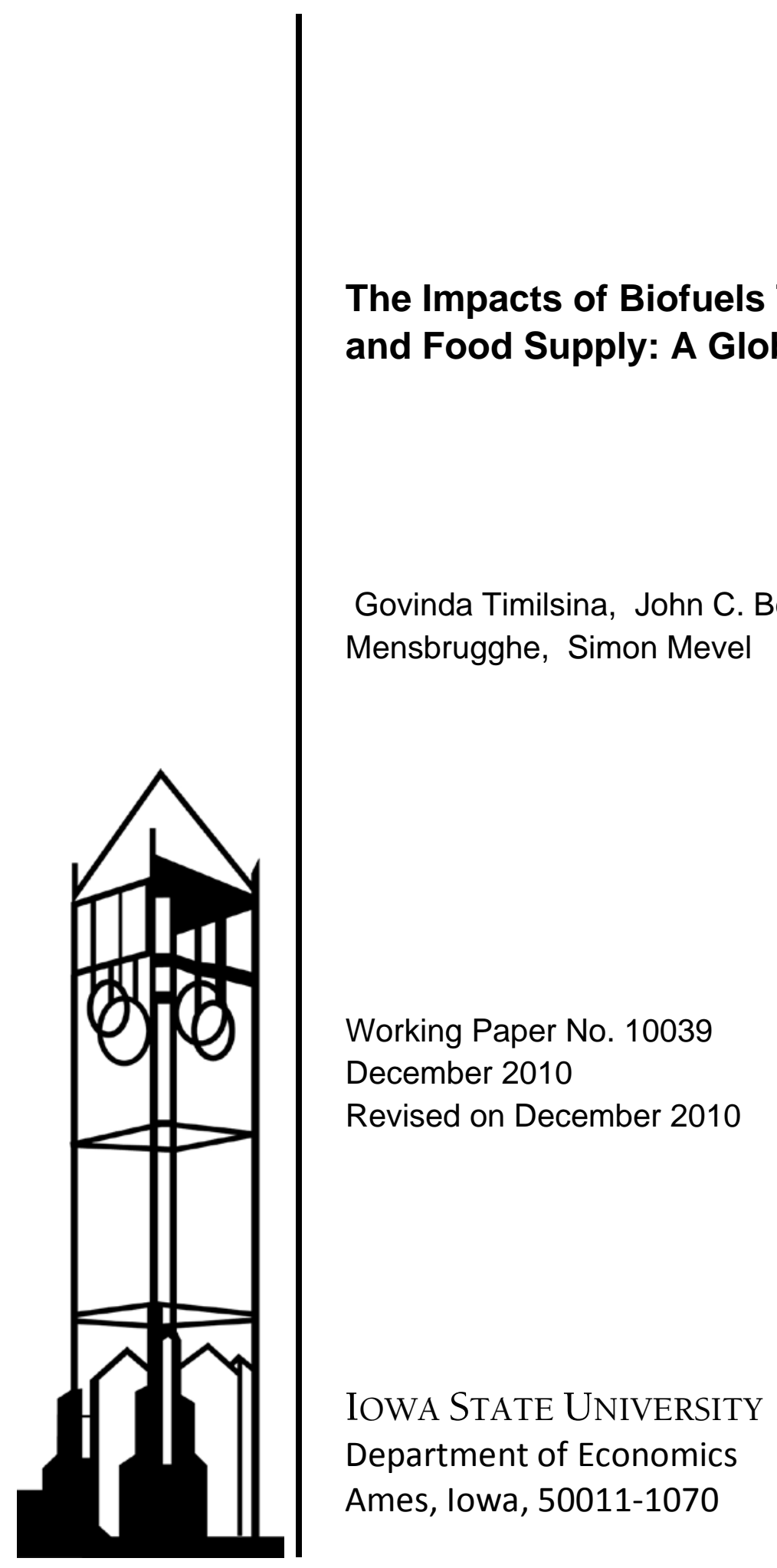

lowa State University does not discriminate on the basis of race, color, age, religion, national origin, sexual orientation, gender identity, sex, marital status, disability, or status as a U.S. veteran. Inquiries can be directed to the Director of Equal Opportunity and Diversity, 3680 Beardshear Hall, (515) 294-7612. 


\title{
The Impacts of Biofuels Targets on Land-Use Change and Food Supply: A Global CGE Assessment
}

\author{
Govinda R. Timilsina \\ John C. Beghin \\ Dominique van der Mensbrugghe \\ Simon Mevel*
}

December 2010

\begin{abstract}
We analyze the long-term impacts of large-scale expansion of biofuels on land-use change, food supply and prices, and the overall economy in various countries or regions using a multi-country, multi-sector global computable general equilibrium model augmented with an explicit land-use module and detailed biofuel sectors. We find that an expansion of biofuel production to meet the existing or even higher targets in various countries would slightly reduce GDP at the global level but with mixed effects across countries or regions. Significant land re-allocation would take place with notable decreases in forest and pasture lands in a few countries. The expansion of biofuels would cause a moderate decrease in world food supply and more significant decreases in developing countries like India and Sub-Saharan Africa. Feedstock commodities (sugar, corn and oil seeds) would experience significant increases in their prices in 2020, but other price changes are small.
\end{abstract}

Keywords: Biofuels, ethanol, biodiesel, land use, food supply, food prices, CGE model, impacts

JEL Code: Q42, Q48, Q54, Q17, D58

\footnotetext{
*Affiliations: Timilsina is senior economist at the World Bank; Beghin is Marlin Cole Professor of international agricultural economics at Iowa State University, van der Mensbrugghe and Mevel are lead economist and research analyst at the World Bank. Corresponding author: Govinda Timilsina: Development Research Group, The World Bank. 1818 H Street, NW. Washington, DC 20433, USA. Tel: 1202473 2767. Fax: 1202522 1151. E-mail: gtimilsina@worldbank.org. The views and findings presented here should not be attributed to the World Bank. We thank Masami Kojima, Peter Berck, Mark Rosegrant and Stephen Mink for their valuable comments and David Zilberman, Jean Christophe Bureau, Harry de Gorter, Amani Elobeid, Jay Fabiosa, Alexandre Gohin, Will Martin and John Nash for discussions. We acknowledge the Knowledge for Change Program (KCP) Trust Fund for the financial support. Beghin acknowledges support from the Marlin Cole Professorship.
} 


\section{Introduction}

The last four years have been characterized by extreme price movements in commodity markets. From 2006 to summer 2008, commodity prices increased to historically record-high levels. Since, this commodity bubble subsided; nevertheless agricultural commodity prices have remained high, well above historical trend. These recent sharp rises in agricultural and primary food prices have made real the issue of food-biofuels trade-offs. A key question to investigate is: is the global biofuel expansion creating further food scarcity and hunger, especially among regions and population at risk? In addition, a second concern has emerged regarding the environmental impact of biofuels, and in particular, their local and global impact on land-use and carbon release. Many stakeholders now question the urgency of further developing biofuels because of this triple global interface between food, bioenergy and the environment (Searchinger et al. (2008); and Runge and Senauer (2007)). We investigate some of these concerns and provide some answers to these complex questions, with a focus on the impact of biofuel expansion on land allocation and the resulting impact on food supply and affordability.

In the midst of the price surge of spring 2008, analysts have suggested that the production of biofuels was one of the key reasons for the spike in global food prices (Mitchell (2008); and Rosegrant et al. (2008), among others). However, there is no established consensus on the causes of the recent food crisis and its potential determinants, which include the surge in biofuels, cost-push factors such as the increase in energy and fertilizer prices, high food consumption growth in large emerging economies, the role of market restrictions, investment funds' hoarding, and the devaluation of the US dollars on dollar-denominated commodity prices (Timmer (2008); and Banse et al. (2008b)).

Similarly, there are many questions relating to the long-term impacts of increased biofuels production - how does the expansion affect food availability and prices in the long run? Who would 
gain and lose from potentially higher commodity and food prices, where would agricultural production change? Will biofuel production generate income and reduce poverty despite higher food prices? What are the land supply responses? Our paper examines some of these long-term issues using a global dynamic computable general equilibrium (GDCGE) model augmented with an explicit land allocation module and detailed biofuel production sectors.

The GDCGE model accounts for the competition between biofuel and food industries for agricultural commodities. The major biofuel feedstock is composed of corn, sugarcane, soybean oil, palm oil, and other vegetable oils and their backward linkages to oilseeds. The approach pays particular attention to productivity gains through increases in yield and to changes in land allocation between various uses between forest land and agriculture and within agricultural uses. Yield assumptions have been contentious in the biofuel literature because of their implications for land expansion (Searchinger et al., 2008; and Keeney and Hertel, 2008). An expansion of biofuels would result in diversion of land used for other agricultural commodities towards production of biofuel feedstock. Grassland and forest land could be converted to agricultural land to produce biofuel feedstock. Yield responses to higher prices mitigate these land diversions and reallocations although the exact magnitude of these responses remains uncertain. This uncertainty is an important caveat qualifying our results.

Our analysis aims first, to estimate land-use mix at national, regional, and global levels in the baseline scenario. This is followed by the estimation of land-use mix under two main scenarios of biofuels penetration in the global energy supply mix for road transportation. All types of land such as crop land, grass land, and forest land are included. The study assesses, at national, regional, and global levels, the impacts of the increased production of biofuels on land allocation, agricultural and food production, and their prices.

Finally, this study also investigates the role of increased demand for biofuel feedstock as a 
promoter of monoculture of some feedstock. How does the biofuel expansion impact rainforest, wetlands, and other biodiversity resources? Existing studies (e.g., Sielhorst et al., 2008) argue that the expansion of biofuels seriously impacts wetlands. In Indonesia, deforestation is linked with an increased production of palm oil, a feedstock for bio-diesel. Thus, this study examines impacts of biofuels on various types of land and natural resources at national, regional, and global levels.

We find that the impact of a considerable global expansion of biofuel production on agricultural prices is moderate, except for sugar crops, which increase by about 9.2 to $11.6 \%$. Food prices and supplies are moderately affected by these increases in biofuels unlike predicted by earlier estimates (Mitchell, 2008; and De Santi, 2008). However, the land use impact is more significant with large expansion of crop land offset by reduction in forest and pasture. Within the land used for crops, a sizeable reshuffling of land takes place to accommodate the expansion of feedstock crops for biofuels. Decreases in forest areas are notable in Brazil and Canada. These results do not exclude the occurrence of a perfect storm in the short term as the one that occurred in 2008 with a spike in prices and adverse consequences for food security and poverty. Our results should be carefully considered as estimated long-term impacts and do not shed light on these potential short-term food price crises.

\section{Literature Background}

Following the price hikes of spring 2008, Mitchell (2008) and Timmer (2008 provided ad-hoc insightful background analysis of key factors affecting food prices including the role of the emergence of biofuels and the resulting increase in agricultural feedstock demand. These papers did not formally address the global multi-crop land allocation problem. Recent investigations based on the FAPRI model (Elobeid and Tokgoz, 2008; Fabiosa et al. (2010); Searchinger et al. (2008); and Tokgoz et al. (2007)) estimate the impact of various scenarios of biofuel expansion on prices and 
land use. In these partial equilibrium investigations, yields are assumed constant and most of the production changes occur through land allocation changes, overstating the land and price effects. Land allocation is country specific and depends on local crop mix, suitability of land and relative crop prices. There is no explicit modeling of land markets. Despite these rigidities global land expansion and agricultural price effects are surprisingly moderate, partly because supply adjustments are substantial via stock adjustment, flexibility in existing land use, and world market response to higher prices.

Rosegrant (2008) uses the IMPACT model to analyze several scenarios departing from the recent (2007) biofuel demand. The IMPACT model incorporates land area and yield responses to prices. Rosegrant suggests that biofuel demand contributed about 30 percent of the price increases during the period covering the early 2000s until 2007. The latter figure refers to the effect on the weighted average grain prices, with the largest effect on corn prices (39 percent) but lesser effects on rice and wheat prices (21 and 22 percent, respectively). Roberts and Schlenker (2010) use a calorieequivalent approach to aggregate wheat, corn, rice and soybean production. They estimate aggregate supply and demand for calories and quantify the impact of a biofuel shock equivalent to the current U.S. biofuel mandate on the price of calories from these four crops. They find that the calorie price increases by about 20 percent when accounting for calories saved through dried distillers grains with solubles (DDGS), and 30 percent when abstracting from these by-product calories savings.

General equilibrium analyses provide a more encompassing assessment of the biofuel emergence on the whole economy and food prices because these multiple linkages are explicit in the model. The disadvantages of these analyses are the aggregation of crops in a few sectors, the lack of realistic biofuel policy parameterization, and trade elasticities, which tend to dampen trade responses to changing relative agricultural prices.

Taheripour et al. (2007) look at the impact of biofuel expansion on land through reallocation 
of land into corn, sugar cane, and oilseeds sectors. Biodiesel is treated as crushing oilseeds and producing meal as a byproduct (as DDGS are in the case of ethanol), a drastic assumption. Land supply follows the standard one- level CET assumption incorporated in the GTAP model structure. Land adjusts sluggishly according to relative rents obtained in respective activities. All countries have a common cost structure. The trade matrix is rather limited. It analyzes several policy shocks such as the increase in crude oil prices, the phasing out of MTBE, and biofuel subsidies. Keeney and Hertel (2009) propose a model incorporating land, yield, and trade responses to the biofuel expansion. Aggregate land supply is fixed but land can move across uses according to relative returns. The yield response to prices is a much needed addition. Keeney and Hertel make the yield response explicit. It depends on the substitution between land, labor, capital, and other factors. Keeney and Hertel assume that U.S. imports of ethanol from Brazil increase proportionally to the total U.S. ethanol demand, irrespective of price levels, a questionable assumption as explained later in the modeling section and which has important consequences for land allocation.

Birur et al. (2008) use the GTAP database developed by Lee et al. (2005) and (2008) to analyze the impact of biofuel production on global agricultural markets. The latter authors decompose land into 18 agro-ecological zones (AEZs). Birur et al. consider 3 biofuels, ethanol from grains, ethanol from sugar-crops, and biodiesel from vegetable oils. They treat the 2 ethanol productions as imperfect substitutes. The crops considered are coarse grains, oilseeds, sugarcane, other grains, and other agriculture. Crops, grazing, and forestry use the total land endowment. Composite land supply is made of land in the 18 AEZs, which are treated as highly substitutable (CES with an elasticity of substitution of 20). Within any AEZ, land shifts between forest, pasture, and crops with some CET value of -0.11 . Within crops, land shifts moving with a CET elasticity of 0.5. Land owners maximize returns on land by choosing an optimum allocation across uses according to relative returns. The nested CET tree structure of land supply essentially parallels 
Keeney and Hertel within each AEZ.

Banse et al. (2008a) use a modified GTAP-E model which incorporates a refined 3-level nested approach to land allocation first proposed by Huang et al. (2004). Banse et al. analyze the impact of the EU biofuel directive on agricultural markets. Gohin (2007) and Bouët et al. (2008) analyze the impact of the EU Biofuel directive. Gohin's analysis accounts for set-a-side land coming back into agricultural production and for the impact on the livestock sector. Gohin's land supply follows that of Keeney and Hertel (2009). Bouët et al. use a land decomposition based on AEZ data.

\section{Land Module for Biofuel Modeling}

Ethanol and biodiesel are the two major commercial biofuel considered in our model. The major feedstocks used for ethanol are grains, sugar beet, sugarcane, and molasses. For biodiesel, the major feedstocks are vegetable oil from rapeseed, soybean, and palm oil. The major feedstock for ethanol in warmer countries is sugarcane, whereas grains are used in more temperate climates (corn, but also wheat, and barley), and to a much lesser extent sugar from sugar beet. Other feedstock types are not yet used in commercial operations and are not expected to be for the foreseeable future. Biodiesel production exists because of policy mandates and subsidies but it is not currently profitable without subsidies. All countries growing grains, oilseeds, or sugar crops are potentially affected by the biofuel expansion through the transmission of higher world prices for these commodities as well as the changes in their relative magnitude, even though they may not produce biofuel.

\section{Modeling approach}

The overall structure of the CGE model is briefly presented in Appendix A. We direct our discussions on the land-use component of the model as the paper mainly deals with impacts on land-use change and food supply. We refer the interested reader to van der Mensbrugghe (2008) for the detailed description of the model as well as to Appendix B for a description of the modifications 
associated with the biofuel module. The following sections describe the approach to land allocation adopted in the analysis.

Our analysis uses an acreage response model paralleling Birur et al. (2008), Keeney and Hertel (2009) and Lubowski et al. (2006), but with significant departures regarding the CET assumptions impacting land allocation decisions. For the latter we follow a nested approach to land allocation reminiscent of Huang et al. (2004) and as applied by Banse et al. (2008a).

Huang et al. (2004) and Banse et al. (2008a) provide a more realistic land allocation tree and nesting than Keeney and Hertel do. The nested structure allows for different CET elasticities for subsets of agricultural activities and crops. For each country, a specific CET tree is designed to capture various and distinct subsets of crops competing for the same agricultural land with a higher elasticity of transformation within nests and lower ones between crop nests. As noted by Huang et al., land devoted to rice in most countries does not directly compete with other crops. Similarly, we note that sugarcane production competes with a limited number of crops. By contrast, oilseeds and grain productions are in direct and strong competition with each other in most countries where they are produced. Hence, consistent with this fact, we lump them within the same nest and to allow for greater land mobility between them.

As in Birur et al., we assume that on the top nest, forest, pasture, and crops compete for the same land. Then, we depart from the simple nesting of crops of Birur et al. We assume that crops are divided into land going to four crop categories (rice, sugar-crops, an aggregate grains and oilseeds, and an aggregate other crops). These four crop categories form a second nest. Finally, grains and oilseeds constitute a last nest with wheat, corn, other coarse grains, and oilseeds as competing for the use of the same land. This structure accounts for the relative isolation of rice and sugar cane areas, and the geographical proximity and competition between coarse grains and food grains, and oilseeds for the same land. Figure 1 illustrates the nesting. 


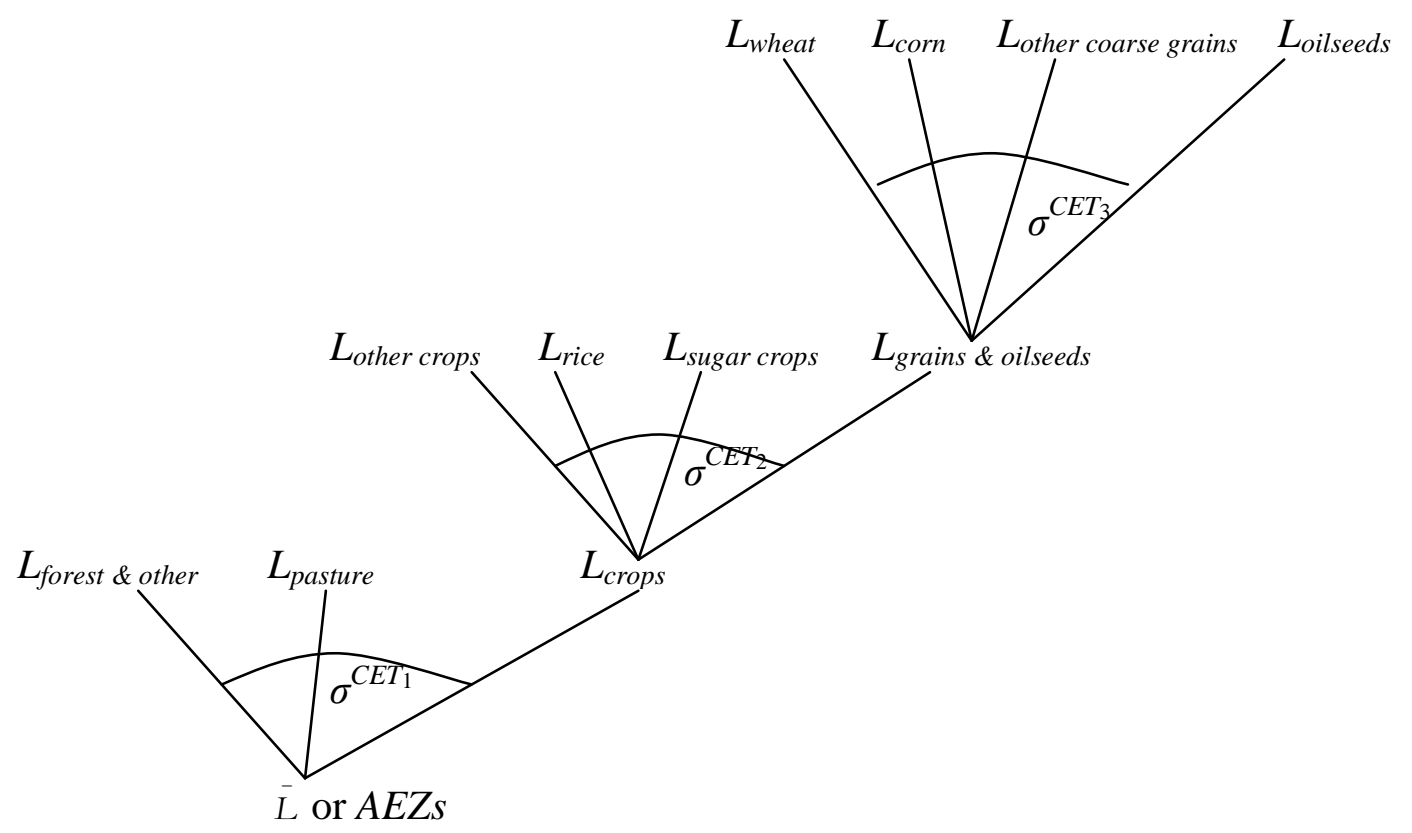

Figure 1. Land allocation

Next, we derive the price responses of land to unit revenue for the nested land allocation explained previously. We first introduce a simple land allocation within a single nest, and then extend the intuitive structure to the 3-nest actual structure. The simple structure mimics what happens within each nest holding constant the land allocated to the nest. The simple structure also describes what happens in the top nest, for which the land constraint is fixed. For the two subsequent nests, the total land allocated to the respective nest is price dependent and will respond to price changes. This additional price response is then explained for the two nests.

\section{Derivation of the land supply specification}

We start by assuming first a single nest with a total land constraint $A$. Under such setup, equation (1) shows the first optimality condition for land allocation to activity $i, L_{i}$, that maximizes land revenues under an aggregate land constraint $A$. The land constraint is shown in equation (2). The land constraint accounts for land quality differences. The CET transformation elasticity, $\sigma^{C E T}$, is negative. The composite price $P P$ reflects the composite revenue per unit of land in aggregate land $A$. 


$$
L_{i}=\theta_{i}^{\sigma} \quad{ }^{C E T} A\left(\frac{P P}{R_{i}}\right)^{\sigma^{C E T}} \text {, with }
$$

$$
P P=\left[\sum_{i} \theta_{i}^{\sigma^{C E T}} R_{i}^{1-\sigma^{C E T}}\right]^{\frac{1}{1-\sigma^{C E T}}}, \text { and }
$$

$$
A=\left\lfloor\sum_{i} \theta_{i} \frac{{L_{i}}^{\frac{\sigma^{C E T}-1}{\sigma^{C E T}}}}{]^{\frac{\sigma^{C E T}}{\sigma^{C E T}-1}}}\right\rfloor^{.}
$$

The responses of land activities with respect to changes in unit revenues, $\varepsilon_{i j}=d \ln L_{l} / d \ln \mathrm{R}_{j}$, are derived from the log-differentiation of equation (1) holding the land constraint $A$ constant. The responses are shown in equation (3):

(3) $\varepsilon_{i j}=-\sigma^{C E T}\left(\delta_{i j}-\alpha_{j}\right)$,

where $\delta_{\mathrm{ij}}$ indicates the kronecker delta, and $a_{j}$ indicates the share of revenue from activity $j$ in total land revenues.

Next, we derive the land supply price elasticities for the 3-nest structure. The optimization problem assumes a sequence of separable decisions given prices for the respective choice within the nest and following a set of constraints for each respective nest $\left(A, A_{n 2}\right.$, and $\left.A_{n 3}\right)$. We start from the top nest allocating land $A$ between forest, pasture and aggregate crops $\left(A_{n 2}\right)$ given returns $R_{i}(i=f, p$, n2). The second nest allocates land $A_{n 2}$ between rice, sugar crops, an aggregate other crops, and grains and oilseeds $\left(A_{n 3}\right)$ given prices $R_{i}(i=r, s, o c, n 3)$. Last in the third nest, the aggregate land devoted to grains and oilseeds $A_{n 3}$ gets allocated between wheat, corn, other coarse grains, and oilseeds according to returns $R_{i}(i=\mathrm{w}, c, o c g, o s)$. For each nest a structure similar to equations (1) and (2) can be derived by substituting the respective crop choice and returns and aggregate land constraint for the corresponding nest.

In the top nest, land responses to any price $j$ are given by 
(4) $\varepsilon_{i j}=-\sigma^{C E T 1}\left(\delta_{i j}-\alpha_{j}\right), i=f, p, n 2$, and $j=f, p, r, s, o c, w, c, o c g, o s$,

where $\sigma^{C E T 1}$ is the CET elasticity for the top nest and $\delta_{i j}$ and $\alpha_{j}$ are defined as previously. The land allocation responses in the lower nests have two components. A first component derived as in equation (3), or as in the top nest, shows the price effect with the land allocated to the nest assumed fixed, and a second component shows the price response on the land allocated to the nest. It is best to separate the price response by nest. We first derive the price response for land allocated in the second nest to prices in the middle level, lower level, and then in the top level, respectively. This is shown in equations (5):

$$
\begin{aligned}
\varepsilon_{i j} & =-\sigma^{C E T 1}\left(1-\alpha_{n 2}\right)\left(\frac{\alpha_{j}}{\alpha_{n 2}}\right),+-\sigma^{C E T 2}\left(\tilde{\delta}_{i j}-\frac{\alpha_{j}}{\alpha_{n 2}}\right), i=r, s, o c, n 3 \text { and } j=r, s, o c, n 3, \\
(5) \varepsilon_{i j} & =-\sigma^{C E T 1}\left(1-\alpha_{n 2}\right)\left(\frac{\alpha_{j}}{\alpha_{n 2}}\right),+-\sigma^{C E T 2}\left(\tilde{\delta}_{i j}-\frac{\alpha_{j}}{\alpha_{n 2}}\right) i=r, s, o c, n 3 \text { and } j=w, c, o c g, o s
\end{aligned}
$$

with $\tilde{\delta}_{i j}=1$ if $i=n 3$ and $j=w, c, o c g, o s$, else $\tilde{\delta}_{i j}=0$, and

$$
\varepsilon_{i j}=-\sigma^{C E T 1}\left(\tilde{\delta}_{i j}-\alpha_{j}\right), i=r, s, o c, n 3 \text { and } j=f, p,
$$

where $\sigma^{C E T 2}$ is the CET elasticity for the second nest.

Finally, the response for land use in the bottom nest is derived in equation (6) following a similar decomposition of the price response and noting that the land adjustment goes through the three nests for returns of activities in the bottom nest, two nests for prices of activities in the middle nest, and one nest for prices of activities located in the top nest:

$$
\begin{aligned}
\varepsilon_{i j} & =-\sigma^{C E T 1}\left(1-\alpha_{n 2}\right) \frac{\alpha_{j}}{\alpha_{n 2}}-\sigma^{C E T 2} \frac{\alpha_{j}}{\alpha_{n 3}}\left(1-\frac{\alpha_{n 3}}{\alpha_{n 2}}\right)-\sigma^{C E T 3}\left(\tilde{\delta}_{i j}-\frac{\alpha_{j}}{\alpha_{n 3}}\right), \\
i & =w, c, o c g, o s, \text { and } j=w, c, o c g, o s, \\
(6) \varepsilon_{i j} & =-\sigma^{C E T 1}\left(1-\alpha_{n 2}\right) \frac{\alpha_{j}}{\alpha_{n 2}}-\sigma^{C E T 2}\left(\tilde{\delta}_{i j}-\frac{\alpha_{j}}{\alpha_{n 2}}\right), i=w, c, o c g, o s, \text { and } j=r, s, o c, n 3,
\end{aligned}
$$

and with $\tilde{\delta}_{i j}=1$ if $i=w, c, o c g, o s$ and $j=n 3$, else $\tilde{\delta}_{i j}=0$, and

$$
\varepsilon_{i j}=\sigma^{C E T 1} \alpha_{j}, \quad i=w, c, o c g, o s, \text { and } j=f, p, n 2 \text {, }
$$


where $\sigma^{C E T 3}$ is the CET elasticity for the third nest.

The calibration of the three CET elasticities is typically over-identified as many own- and cross-price responses are available for various land uses, but only three of them are required to exactly identify the three CET elasticities. Land revenue shares are directly observed from the land data. We use the rice, sugar, and corn elasticities to identify the CET elasticities. Denoting these own-price responses estimates as $\hat{\varepsilon}_{r r}, \hat{\varepsilon}_{s s} \hat{\varepsilon}_{c c}$, the identification of the CET elasticities $\hat{\hat{\sigma}}^{C E T i}$ is given by solving equations (7) for $\sigma^{C E T 1}, \sigma^{C E T 2}$, and $\sigma^{C E T 3}$ :

7a) $\hat{\varepsilon}_{i i}=-\sigma^{C E T 1}\left(1-\alpha_{n 2}\right)\left(\frac{\alpha_{i}}{\alpha_{n 2}}\right)-\sigma^{C E T 2}\left(1-\frac{\alpha_{i}}{\alpha_{n 2}}\right)-\sigma^{C E T 3} 0, i=r, s$, and

(7b) $\hat{\varepsilon}_{c c}=-\sigma^{C E T 1}\left(1-\alpha_{n 2}\right) \frac{\alpha_{c}}{\alpha_{n 2}}-\sigma^{C E T 2} \frac{\alpha_{c}}{\alpha_{n 3}}\left(1-\frac{\alpha_{n 3}}{\alpha_{n 2}}\right)-\sigma^{C E T 3}\left(1-\frac{\alpha_{c}}{\alpha_{n 3}}\right)$.

\section{Yield elasticity specification}

We follow the derivation of Mullen, Wohlgenant and Farris (1988) as recently applied by Keeney and Hertel to estimate yield responses to prices. The approach derives the comparative statics of changes in input prices on market equilibrium in a competitive agricultural output sector characterized by perfect competition. Variable $X_{i}$ is input $i(i=1, \ldots, k)$ used in a given crop production $Q$ characterized by constant return to scale. In log-differential form, the supply of the input is expressed as

$$
d \ln X_{i}^{s}=\mu_{i} d \ln W_{i},
$$

Where $\mu_{i}$ denotes the price elasticity of supply and $W_{i}$ denote the input price. Under cost minimization in the crop sector, the derived demand for $X_{i}$ is given by (9) in log-differential form:

$$
d \ln X_{i}^{D}=\sum_{j} \sigma_{i j} s_{j} d \ln W_{j}+d \ln Q
$$

where $\sigma_{i j}$ denotes the Allen-Uzawa elasticity of substitution between inputs $i$ and $j$ in the production 
of the agricultural output $Q$; cost shares are denoted by $s_{j}$.

The zero profit equilibrium condition in the output market equates the cost per unit and the price of the agricultural good $P$. This condition is expressed in log-differential form in (10):

$$
d \ln P=\sum_{j} s_{j} d \ln W_{j} .
$$

Market equilibrium in input markets implies that $X_{i}^{s}=X_{i}{ }^{D}$. Combining equations (8) and (9) and the input market equilibrium conditions leads to (11):

(11) $d \ln Q=\sum_{j}\left(\delta_{i j}\left(\mu_{j} / s_{j}\right)-\sigma_{i j}\right) s_{j} d \ln W_{j}, i=1, \ldots k$,

with $\delta_{i j}$ defined again as the kronecker delta. The system of $k$ equations (11) can be solved for the share-weighted changes in input prices $\left(s_{j} d n W_{j}\right)$ as a function of output change $d \ln Q$. The latter result can then be substituted back in equation (10) to eliminate variable $W$. This transformation yields equation (12) which expresses the total response of output $Q$ to changes in output price $P$ induced by changes in input markets:

$$
\begin{aligned}
& d \ln P=\iota^{\prime}[\mathrm{N}-\Omega]^{-1} \iota d \ln Q, \text { or } \\
& d \ln Q / d \ln P=\left[\iota^{\prime}[\mathrm{N}-\Omega]^{-1} \iota\right]^{-1},
\end{aligned}
$$

where $\mathrm{N}$ indicates a diagonal matrix with diagonal elements $\left(\mu_{j} / s_{j}\right), \Omega$ is the matrix of Allen Uzawa elasticities $\sigma_{i j}$, and $\iota$ indicates a unitary column vector. Assuming that the land supply response is zero $\left(\mu_{\text {land }}=0\right)$, then the response $d \ln Q / d \operatorname{nn} P$ provides the yield response to the change in $P$. different time horizons can be considered for the yield response by varying the supply response of all inputs. Large supply responses $\mu_{j}$ indicate a longer run. At the limit an infinite supply of these inputs other than land indicate a long run and provide an upper bound on the yield response.

\section{Trade assumptions impacting land allocation decisions}

The Armington structure of differentiating products is preserved but it assumes higher substitution 
elasticities than those chosen in the Keeney and Hertel approach, since corn, sugarcane, and soybean products are largely homogenous commodities. Although the grain and oilseed aggregates in GTAP are composite commodities, the shocks emanating from the biofuel expansion really involves a small subset of the commodities in these aggregates. Trade response in the real world will be large. Corn from Argentina and Brazil will easily substitute for U.S. corn, and Brazilian soybean products will substitute perfectly for U.S. soybeans. Similarly, ethanol trade substitution should reflect nearly perfect substitution between Brazilian ethanol, and domestic ethanol in the demand structure of any importing country, including the U.S.

A second pivotal trade policy assumption is to correctly model U.S. biofuel trade policy. In particular, the U.S. biofuel trade policy includes an ethanol ad valorem tariff of 2.5 percent and a specific tariff or 54 cents/gallon. As long as the U.S. equilibrium ethanol price is within the band of prices established by the Brazilian ethanol price and the same Brazilian price inclusive of the two U.S. tariffs, the U.S. price is endogenously determined by the U.S. market equilibrium and no imports from Brazil will take place. U.S. ethanol is essentially a nontradable good within the price band. If demand expansion pushes the U.S. price to the Brazilian price inclusive of the tariffs, then Brazilian imports take place and the U.S. price moves in tandem with the Brazilian ethanol price. Note that small ethanol imports also occur under a tariff rate quota (TRQ) allowed by the Caribbean Initiative. The TRQ mostly goes under filled. In sum, the U.S. tariff regime blocking Brazilian ethanol imports over a large price band is a key policy element incorporated in our analysis.

\section{Definitions of Baseline and Biofuel Scenarios}

Baseline refers to a scenario where business as usual will continue for economic development, population growth and biofuel development. Existing biofuel policies (e.g. already implemented 
mandates, subsidies and import duties) are part of the baseline. ${ }^{1}$ Future mandates which are incremental to existing mandates are part of targets and included in the scenarios. Like in most dynamic CGE models, three variables -population growth, savings and investment and productivity are the key drivers to generate a baseline. Population growth, depreciation rate of capital stock and productivity growth are exogenous to the model. Growth in aggregate labor supply tracks the working age population (defined as those between 15 and 65 years). Savings and investment determines the overall level of the capital stock along with the rate of depreciation. Sectoral productivity growths are consistent with recent trends (World Bank, 2009). Another exogenous variable in the model baseline is the growth of energy prices, which are calibrated with projections made by the Energy Information Administration of the U.S. Department of Energy. ${ }^{2}$

We define two scenarios. The first scenario considers the implementation of biofuel targets announced by countries (hereafter "AT" scenario) with all targets implemented linearly by 2020 . Some countries meet their announced targets before 2020 due to existing policies (e.g., mandates and subsidies) and market conditions (e.g., U.S., Brazil, Malaysia and South Africa). For these countries we assumed that the AT scenario follows the baseline starting from the year they first become binding. For example, Brazil meets the announced targets before 2009 due to the existing mandate and market conditions therefore the study does not impose any additional policy instrument until 2020 in Brazil. In the United States, the baseline would be equal to AT scenario by 2015 and we assume this is maintained until 2020. Moreover, we abstract from second generation or cellulosic biofuels due to limitations in data and their unknown cost.

The second scenario generally considers a doubling of the announced targets keeping the timing of the implementation of the targets unchanged. In India no increase is added to the AT

\footnotetext{
${ }^{1}$ Impacts of removal of subsidies and import duties have been analyzed in detailed in a separate paper.

2 A module that can represent both conventional and un-conventional oil and gas reserves and production would be ideal; here however, the model used here does not have that capacity. Hence, we used energy price forecasts from other sources instead of generating them endogenously in the baseline.
} 
target level, because the latter is already extremely high (25\% in 2020). We refer to this scenario as the enhanced scenario (hereafter the 'ET' scenario). Table 1 presents biofuel targets in terms of energy contents in both scenarios. Each country has a different initial share and therefore a specific path to the target; for example, Brazil already meets its target by 2010 . Once percentage targets are reached, these targets are constant as shares but they still evolve in terms of physical volume as transportation energy consumption changes over time. The study assumes government revenue neutrality, in other word, governments need to find additional revenue to finance the subsidies required to realize the targets. Taxation of gasoline and diesel would be the best source as it not only provides needed revenue but also helps lower the level of subsidies on biofuels. The revenue neutral tax rates turn out to be small due to the large tax base.

Table 1. Scenarios: Share of biofuels in the total liquid fuel demand for transportation

\begin{tabular}{|l|c|c|c|c|c|c|}
\hline Country/Regions & \multicolumn{2}{|c|}{ Target $(\%)^{a}$} & \multicolumn{2}{c|}{ Subsidy Rated $(\%)$} & \multicolumn{2}{c|}{ Tax Rate (\%) } \\
\hline & AT & ET & AT & ET & AT & ET \\
\hline Australia and New Zealand & 1.23 & 2.46 & 36.71 & 57.92 & 0.16 & 0.34 \\
\hline Japan & 0.60 & 1.20 & 14.85 & 45.76 & 0.05 & 0.19 \\
\hline Canada & 4.10 & 8.20 & 50.07 & 68.86 & 0.56 & 1.08 \\
\hline United States ${ }^{b}$ & 4.07 & 8.14 & 0.96 & 29.78 & 0.04 & 0.84 \\
\hline France & 10.00 & 20.00 & 58.36 & 74.57 & 1.11 & 2.65 \\
\hline Germany & 10.00 & 20.00 & 43.35 & 65.08 & 1.03 & 2.78 \\
\hline Italy & 10.00 & 20.00 & 65.32 & 78.40 & 1.21 & 2.45 \\
\hline Spain & 10.00 & 20.00 & 61.01 & 75.13 & 1.12 & 2.21 \\
\hline UK & 10.00 & 20.00 & 74.00 & 83.08 & 1.00 & 1.75 \\
\hline Rest of EU \& EFTA & 10.00 & 20.00 & 75.62 & 84.83 & 1.09 & 1.99 \\
\hline China & 3.65 & 7.30 & 22.57 & 50.01 & 0.45 & 1.40 \\
\hline Indonesia & 5.00 & 10.00 & 22.10 & 50.91 & 3.39 & 3.47 \\
\hline Malaysia & 1.81 & 3.62 & 1.79 & 39.41 & 0.02 & 0.60 \\
\hline Thailand & 5.20 & 10.40 & 51.92 & 73.95 & 0.92 & 1.92 \\
\hline Rest of East Asia \& Pacific & 1.49 & 2.98 & 42.45 & 58.10 & 0.22 & 0.39 \\
\hline India & 16.70 & 16.70 & 53.26 & 53.26 & 3.35 & 3.35 \\
\hline Rest of South Asia & - & - & - & - & - & - \\
\hline Argentina & 5.00 & 10.00 & 52.27 & 70.43 & 0.87 & 1.61 \\
\hline Brazilc & 9.50 & 19.00 & - & 2.48 & - & 0.83 \\
\hline Rest of LAC & 1.48 & 2.96 & 16.74 & 47.97 & 0.10 & 0.41 \\
\hline Russia & - & - & - & - & - & - \\
\hline
\end{tabular}




\begin{tabular}{|l|c|c|c|c|c|c|} 
Rest of ECA & - & - & - & - & - & - \\
\hline MENA & - & - & - & - & - & - \\
\hline South Africa & 2.00 & 4.00 & 0.88 & 10.73 & 0.03 & 0.68 \\
\hline Rest of Sub-Saharan Africa & - & - & - & - & - & - \\
\hline
\end{tabular}

a Refers to ratio of consumption of ethanol and biodiesel to consumption of ethanol, biodiesel, gasoline and diesel in road transportation (the consumption are expressed in energy unit). ${ }^{b}$ Mandates for cellulosic ethanol are not included. ${ }^{c}$ Since the biofuels penetration in the baseline is same as that in AT scenario, no additional subsidy would be required to meet this scenario. ${ }^{\mathrm{d}}$ Subsidies equivalent to the targets and corresponding taxes on gasoline and diesel required to finance the subsidies in year 2020. EFTA stands for European Free Trade Association; LAC, EAC and MENA refer to respectively, Latin America and Caribbean, Eastern Europe and Central Asia and Middle East and North Africa.

\section{Simulation Results}

We present key impacts on production and prices of biofuels and agricultural commodities, land use mix and food supply. Whenever possible we relate our results to the existing literature.

Table 1 presents the subsidy level or shadow price required if the mandates or targets are to be met through an economic instrument for the two scenarios. ${ }^{3}$ The subsidy rate varies across countries depending upon the biofuels penetration gaps between the scenarios and the baseline. Most European countries exhibit a higher subsidy level because their 10\% target by 2020 is much higher than their biofuel penetration levels in the baseline. On the other hand, the level of subsidy in the United States is small as its biofuels target is small and would nearly be met by 2020 due to the existing subsidy.

We present results in deviation from the baseline trajectory both in percent deviation from the model baseline, and in billion of dollars in 2004 prices when relevant. ${ }^{4}$ We focus the discussion on the ET scenario which represents a larger shock on the world economy than the AT scenario does. The ET scenario leads to a $13.1 \%$ share of biofuels in the total consumption of liquid fuels in the transport sector. We begin by explaining what each shock represents in biofuel expansion in deviation from the baseline followed by discussions on land-use and food supply impacts as well as

\footnotetext{
${ }^{3}$ There could be other economic instruments, such as taxes on gasoline and diesel, taxes on ethanol -gasoline and biodiesel-diesel blends. However, we considered subsidy as it would be the most direct economic instrument to meet the targets. Several existing studies have also adopted the same approach.

${ }^{4}$ The change in absolute values (i.e., billion dollars here) is relevant in cases where the percentage change numbers, appear to be extremely high due to small base.
} 
food price consequences. We present key results in this section; detailed results from the main as well as sensitivity analysis are available from the authors upon request.

\section{Impacts on biofuels production and trade}

The AT scenario induces significant changes in biofuel production although some of these are moderate in several countries with sizeable biofuel programs. The latter countries have been implementing their biofuel targets for several years. Global biofuel production increases by $64.5 \%$ in 2020 compared to what it would have been in the baseline with the largest changes in the EU, China, Thailand, and India. By contrast, the ET scenario has much larger effects in most countries, than the AT scenario does, except India. This is by design since the penetration targets are doubled or more. The targets in the ET scenarios translate into a vast increase in world biofuel production and use ( $+153.2 \%$ or $\$ 92.1$ billion at 2004 prices) with the largest increases in the EU and EFTA countries ( $\$ 65.8$ billion), Brazil ( $\$ 7.9$ billion), and China ( $\$ 8.7$ billion) as shown in Table 2 .

Table 2. Increase in Biofuel Production in 2020 in AT and ET Scenarios Relative to the Baseline

\begin{tabular}{|c|c|c|c|c|}
\hline \multirow[t]{2}{*}{ Country/Regions } & \multicolumn{2}{|c|}{ AT } & \multicolumn{2}{|c|}{ ET } \\
\hline & US\$ Billion & $\%$ & US\$ Billion & $\%$ \\
\hline World total & 38.8 & 64.5 & 92.1 & 153.2 \\
\hline High-income & 25.4 & 89.6 & 67.7 & 238.8 \\
\hline Australia and New Zealand & 0.0 & 20.9 & 0.2 & 145.2 \\
\hline Japan & 0.0 & 3.8 & 0.1 & 28.3 \\
\hline Canada & 0.2 & 45.0 & 0.8 & 167.3 \\
\hline United States & 0.2 & 1.1 & 0.8 & 4.2 \\
\hline France & 7.7 & 268.0 & 19.8 & 691.2 \\
\hline Germany & 3.3 & 112.0 & 11.1 & 371.2 \\
\hline Italy & 2.7 & 321.0 & 7.0 & 842.2 \\
\hline Spain & 2.8 & 367.5 & 7.3 & 959.3 \\
\hline UK & 2.7 & 500.1 & 6.1 & $1,135.9$ \\
\hline Rest of EU \& EFTA & 5.7 & 538.8 & 14.5 & $1,355.9$ \\
\hline Middle \& Low-income & 13.4 & 42.1 & 24.4 & 76.8 \\
\hline China & 2.2 & 55.4 & 8.7 & 217.9 \\
\hline Indonesia & 0.3 & 49.2 & 1.4 & 210.1 \\
\hline Malaysia & 0.0 & 0.5 & 0.0 & 1.3 \\
\hline
\end{tabular}




\begin{tabular}{|l|c|c|c|c|} 
Thailand & 0.4 & 88.1 & 1.3 & 294.7 \\
\hline Rest of East Asia \& Pacific & 0.1 & 53.7 & 0.4 & 155.1 \\
\hline India & 3.9 & 205.8 & 3.9 & 207.4 \\
\hline Rest of South Asia & 0.0 & 58.1 & 0.2 & 213.5 \\
\hline Argentina & 0.1 & 45.9 & 0.6 & 189.9 \\
\hline Brazil & 6.3 & 31.1 & 7.9 & 39.2 \\
\hline Rest of LAC & 0.0 & 4.2 & 0.2 & 51.4 \\
\hline Russia & 0.0 & -1.3 & -0.1 & -3.0 \\
\hline Rest of ECA & 0.0 & -0.9 & 0.0 & -2.5 \\
\hline MENA & 0.0 & -1.2 & 0.0 & -2.8 \\
\hline South Africa & 0.0 & 0.5 & 0.0 & 0.7 \\
\hline Rest of Sub-Saharan Africa & 0.0 & 0.1 & 0.0 & -1.8 \\
\hline
\end{tabular}

Countries like Brazil, China, France, and India would realize relatively higher production of biofuels. While the production increase in Brazil is mainly driven by international trade, the increases in other countries are driven by domestic targets. Some countries which do not have biofuel targets could experience decrease in production (of biofuels) due to increased export demand for their biofuel feedstock, but the reductions are negligible. Table 3 presents scenario impacts on international trade of biofuels. The expansion of biofuels would induce an expansion of biofuel trade of $259 \%$ under the AT scenario. The expansion of biofuel trade volume under the ET scenario is twice that of the AT scenario. Countries that would experience the highest level of imports of biofuels include India and some EU countries. Countries that would experience the highest level of exports of biofuel include Brazil and some EU countries, namely France and Germany. These countries can expand their biofuel feedstock production.

Table 3. Change in Biofuel Trade (\%) relative to the baseline in 2020 - by region

\begin{tabular}{|l|c|c|c|c|}
\hline \multirow{2}{*}{ Country/Regions } & \multicolumn{2}{|c|}{ Imports } & \multicolumn{2}{c|}{ Exports } \\
\hline & AT & ET & AT & ET \\
\hline World total & 258.7 & 520.7 & 258.7 & 520.7 \\
\hline High-income & 310.9 & 794.2 & 370.6 & 934.7 \\
\hline Australia and New Zealand & 0.0 & 0.0 & 0.0 & 0.0 \\
\hline Japan & -1.6 & 19.1 & 0.0 & 0.0 \\
\hline Canada & 65.5 & 249.1 & 0.3 & 0.5 \\
\hline United States & 0.6 & 2.3 & 38.3 & 163.4 \\
\hline
\end{tabular}




\begin{tabular}{|c|c|c|c|c|}
\hline France & 153.8 & 564.8 & 486.1 & $1,204.7$ \\
\hline Germany & 78.9 & 303.2 & 873.5 & $2,220.7$ \\
\hline Italy & 319.7 & 820.0 & 0.0 & 0.0 \\
\hline Spain & 362.1 & 909.6 & 375.9 & $1,017.4$ \\
\hline UK & $1,042.4$ & $2,556.6$ & 472.7 & $1,096.3$ \\
\hline Rest of EU \& EFTA & 637.2 & $1,527.9$ & 82.7 & 332.3 \\
\hline Middle \& Low-income & 203.6 & 232.6 & 181.1 & 234.1 \\
\hline China & 0.0 & 0.0 & 25.9 & 79.5 \\
\hline Indonesia & 0.0 & 0.0 & 1.3 & 3.6 \\
\hline Malaysia & 0.0 & 0.0 & 1.7 & 4.9 \\
\hline Thailand & 0.0 & 0.0 & -39.0 & -77.4 \\
\hline Rest of East Asia \& Pacific & 54.5 & 170.1 & 0.0 & 0.0 \\
\hline India & 420.3 & 425.8 & 0.0 & 0.0 \\
\hline Rest of South Asia & 0.0 & 0.0 & 306.1 & $1,134.2$ \\
\hline Argentina & 0.0 & 0.0 & 1.5 & 26.5 \\
\hline Brazil & 0.0 & 0.0 & 198.5 & 250.6 \\
\hline Rest of LAC & 0.0 & 46.2 & 0.0 & 0.0 \\
\hline Russia & 0.0 & 0.0 & 0.0 & 0.0 \\
\hline Rest of ECA & -5.8 & -8.1 & 0.0 & 0.0 \\
\hline MENA & -2.2 & -4.9 & 0.0 & 0.0 \\
\hline South Africa & 0.0 & 0.0 & 0.0 & 0.0 \\
\hline Rest of Sub-Saharan Africa & -3.6 & -6.0 & 0.0 & 0.0 \\
\hline
\end{tabular}

Note: The large percentage changes in many countries are due to the small base in the baseline.

\section{Impacts on agricultural production and trade}

The effects on agricultural output are shown in Table 4. Every country or region considered experience an agricultural expansion. Even the countries which experience decrease in biofuel production would see an increase in agricultural production due to increased export demand for biofuel feedstock. EU countries exhibit the highest percentage increase in agricultural outputs.

Agricultural output reaches a global expansion of 1.1 percent ( $\$ 38.3$ billions) in 2020 in the ET scenario. All crops, except rice ${ }^{5}$, increase in the ET scenario, and notably so for sugar crops (13.5\%), other coarse grains $(11.2 \%)$, oilseed $(7.6 \%)$, corn $(4.1 \%)$, and wheat $(3.7 \%)$. Rice production falls notably in Brazil and Thailand because competing crops such as sugar are more profitable. The strong expansion of biofuel in the ET scenario explains this agricultural expansion of

\footnotetext{
${ }^{5}$ Rice production decreases as land is reallocated towards oilseeds, sugar, and grains. This will be discussed in detail later.
} 
feedstock crops. The sugar expansion takes place principally in the EU, Thailand, Brazil, and India. The global increase in grains takes place in the EU with wheat in France, other coarse grains in Spain, and corn in the United States. limited expansion takes place in grains in Middle and LowIncome countries except for corn production in China. This limited expansion in grains occurs because other crops such as sugar cane are more profitable in many of these countries. The Armington structure is also partially responsible for these localized expansions. Oilseed expansion is strong in EU countries (France, Germany and Italy) and Brazil. Oilseed production expands because vegetable oil is the feedstock for biodiesel. Malaysia would have expansion of palm oil production as reflected in the increase in oilseed production and food processing related to oilseeds. Finally, livestock production contracts in most countries as the cost of feed goes up. Protein meal is slightly cheaper than in the baseline but it does not offset the more expensive feed grains.

Our results on agricultural impact are close to those of Bouët et al. (2008). They obtain large increases in EU sugar crops and relatively moderate increases in grains. They also show a vast expansion of oilseeds as we do, but with a stronger expansion in Brazil, reflecting the high global integration of oilseeds markets across countries and oil types. Gohin (2009) also obtains sizeable expansion of oilseed production in the EU induced by EU biodiesel targets and an expansion of livestock production from the cheaper protein in feed. Our results on agriculture output are also close to those of Kretschmer et al. (2009) and Al-Riffai et al. (2010) and consistent with those of Fischer et al. (2009).

Changes in agricultural trade are notable and illustrate the important role of global trade to mitigate domestic shocks in biofuel and feedstock markets. These are shown in Tables 5 and 6. All countries with biofuel targets would experience increases in total trade of agricultural commodities, mostly commodities used for biofuel feedstock and which experience the largest price changes. The increase in agriculture imports would be relatively higher in EU countries and India. The percentage 
increase in sugar and oilseeds imports would be relatively higher as compared to imports of other agriculture commodities. The expansion of biofuels would cause substantial decrease in exports of agriculture commodities in countries such as India, Thailand and the United Kingdom. On the other

hand, export of agriculture commodities, mainly biofuel feedstock, would increase in countries like Brazil, Argentina, Russia and many regions, such as Sub-Saharan Africa, MENA, and South Asia (except India). These significant two-way trade effects can be attributed to various factors.

The heterogeneity of the basket of commodities, such as oilseeds and grains of different quality, distance, and location of production and net surpluses and deficits areas prevailing in many countries contribute to the trade patterns. Within a large country, surplus and deficits areas can export and import more cheaply than they can access the domestic market. In the EU, intra-EU trade in oilseed is quite large with EFTA countries and Germany importing from other EU countries like France. Brazil and the U.S. extend their exports of oilseeds as they are the world's largest soybean producers and exporters.

\section{Impacts on prices of agriculture and other commodities}

Changes in world prices are detailed in Table 7 . The changes vary from $-1.7 \%$ (crude oil) to $9.7 \%$ (sugar cane) under the ET scenario. These large increases for sugar cane prices are followed by higher prices for ethanol (4.1\%), corn (3.6\%), biodiesel (3.5\%), oilseeds $(2.9 \%)$, wheat $(2.3 \%)$, and other coarse grains $(2.2 \%)$. Processed food prices change moderately $(0.5 \%)$. The prices of gasoline and diesel products fall by $1.4 \%$. These lower energy prices mitigate the higher cost of farm ingredients in processed food. We also compute price multipliers (percent change in price/percent change in world biofuel production), to gauge the price impact of the two scenarios. The sugar price multipliers are the largest at 22.3\% (AT scenario) and 12.3\% (ET scenario). The value of 22.3\% could be interpreted as the percent increase in price if world biofuel doubled. The next multiplier is for the ethanol price with a multiplier of $6.9 \%$ for the AT scenario. The multipliers for the aggregate 
agricultural price index are 5.5\% and 4\%, respectively for the AT and ET scenarios. The price multipliers for other commodities are moderate. For example, the processed food price multiplier is $0.5 \%$, again clearly showing the moderate impact biofuels have on processed food prices. These small changes do not preclude higher localized price changes. Land prices (not shown) do change a lot in the EU (France, and also the UK and Spain) where land devoted to sugar crops and oilseeds sometimes more than double in value. Our results show larger effects than those of Kretschmer et al. (2009) and Al-Riffai et al. (2010) because they only consider EU biofuel policies whereas we look at global changes in policies.

\section{Impacts on land use mix}

Changes in aggregate land allocations between forest, pasture, and crops under both scenarios are shown in Table 8. Results for the AT scenario show similar patterns to those of the ET scenario but muted by the smaller biofuel targets. Aggregate effects in the 3 major land uses are small in terms of percentage change from the baseline, less than 1 percent in absolute value in most countries, except in Brazil, Thailand and the EU (Germany, France, Spain, and the UK). For the latter, effects are relatively larger, between 1.1 and 5.1 percent in absolute value for changes in forest and pasture. Some countries show significant change in land-use mix. For example, France exhibits 5.1\% and 4.1\% decreases in forest and pasture lands. There is a move away from pasture and forest toward a higher allocation of land to cropland in virtually all countries. In the ET scenario, the targets ramp up land allocation for the crops serving as feedstock in biofuels away from pasture and forest and non-feedstock crops. This is notable in the EU (The UK and France), Thailand, South Africa, India, and Brazil where the loss of forest and pasture is significant.

Figure 2 shows the change in the distribution of forest land by country for both scenarios. The ET scenario leads to nearly 18.4 million hectares of forest loss as compared to the baseline in 2020 with the largest losses taking place in Brazil and Canada. 
Table 4. Change in agricultural output (\%) relative to the baseline in 2020

\begin{tabular}{|c|c|c|c|c|c|c|c|c|c|c|c|c|c|c|c|c|c|c|}
\hline \multirow[t]{2}{*}{ Country/Regions } & \multicolumn{2}{|c|}{ Agriculture } & \multicolumn{2}{|c|}{ Paddy rice } & \multicolumn{2}{|c|}{ Sugar crops } & \multicolumn{2}{|c|}{ Other crops } & \multicolumn{2}{|c|}{ Wheat } & \multicolumn{2}{|c|}{ Corn } & \multicolumn{2}{|c|}{ Other grains } & \multicolumn{2}{|c|}{ Oilseeds } & \multicolumn{2}{|c|}{ Livestock } \\
\hline & AT & ET & AT & ET & AT & ET & AT & ET & AT & ET & AT & ET & AT & ET & AT & ET & AT & ET \\
\hline World total & 0.4 & 1.1 & -0.2 & -0.3 & 8.1 & 13.5 & -0.1 & -0.1 & 1.3 & 3.7 & 1.0 & 4.1 & 4.5 & 11.2 & 2.4 & 7.6 & 0.0 & -0.1 \\
\hline High-income & 0.8 & 2.0 & 0.1 & 0.2 & 10.1 & 24.0 & 0.0 & -0.1 & 2.6 & 6.9 & 0.7 & 2.5 & 11.1 & 27.3 & 6.3 & 18.3 & 0.0 & 0.1 \\
\hline Australia and New Zealand & 0.3 & 0.8 & 0.1 & 0.3 & 0.4 & 1.8 & 0.3 & 0.6 & 1.0 & 3.5 & 1.2 & 4.8 & 0.9 & 2.7 & 1.9 & 5.3 & 0.2 & 0.5 \\
\hline Japan & 0.3 & 0.9 & 0.1 & 0.2 & 0.5 & 3.2 & 0.4 & 1.1 & 0.9 & 3.1 & 0.4 & 2.2 & 1.1 & 3.2 & 0.9 & 2.7 & 0.3 & 0.8 \\
\hline Canada & 0.3 & 0.8 & 0.0 & 0.0 & 0.2 & 0.6 & 0.0 & -0.4 & 0.7 & 2.3 & 4.0 & 15.1 & 1.0 & 2.7 & 1.1 & 3.0 & 0.0 & 0.1 \\
\hline United States & 0.2 & 0.7 & 0.1 & 0.3 & 0.1 & 0.1 & 0.1 & 0.1 & 1.0 & 3.4 & 0.7 & 2.7 & 0.7 & 1.8 & 0.9 & 2.6 & 0.1 & 0.3 \\
\hline France & 2.6 & 6.3 & -2.0 & -6.0 & 68.8 & 157.5 & -1.4 & -4.3 & 5.2 & 12.7 & 0.2 & 0.5 & 8.2 & 20.0 & 28.3 & 83.0 & -0.5 & -1.6 \\
\hline Germany & 1.3 & 3.6 & 0.0 & 0.0 & 0.7 & 2.9 & 0.0 & -0.5 & 7.1 & 18.1 & 1.8 & 6.8 & 7.7 & 19.7 & 17.5 & 56.9 & 0.1 & 0.2 \\
\hline Italy & 1.1 & 2.9 & 0.6 & 1.4 & 0.4 & 1.0 & 0.4 & 1.1 & 2.2 & 6.4 & 0.8 & 2.4 & 2.1 & 5.9 & 14.1 & 36.4 & 0.4 & 1.0 \\
\hline Spain & 1.5 & 3.9 & -0.1 & -0.3 & 0.5 & 1.8 & 0.2 & 0.5 & 2.6 & 7.6 & 1.3 & 4.8 & 36.8 & 94.8 & 3.2 & 8.7 & 0.2 & 0.4 \\
\hline UK & 1.1 & 2.3 & 0.0 & 0.0 & 19.9 & 49.6 & -0.7 & -1.8 & -1.4 & -2.4 & 0.0 & 0.0 & 62.1 & 134.9 & 11.2 & 30.4 & -0.5 & -1.3 \\
\hline Rest of EU \& EFTA & 0.7 & 1.7 & 0.4 & 1.1 & 3.0 & 7.7 & 0.2 & 0.4 & 2.1 & 5.7 & -0.5 & -0.8 & 9.3 & 23.5 & 7.9 & 21.5 & 0.0 & 0.1 \\
\hline Middle \& Low-income & 0.2 & 0.5 & -0.2 & -0.4 & 7.4 & 10.0 & -0.1 & -0.2 & 0.4 & 1.4 & 1.3 & 5.4 & 0.3 & 0.9 & 0.3 & 1.8 & -0.1 & -0.3 \\
\hline China & 0.2 & 0.5 & -0.1 & -0.2 & 0.2 & 0.3 & -0.1 & -0.4 & 1.1 & 3.2 & 4.7 & 17.9 & -0.2 & -1.9 & -0.2 & -1.0 & -0.1 & -0.3 \\
\hline Indonesia & 0.1 & 0.1 & -0.1 & -0.6 & 8.1 & 29.7 & -0.2 & -0.8 & 0.0 & 0.0 & 0.0 & -0.2 & 0.0 & 0.0 & 0.1 & 0.5 & -0.1 & -0.5 \\
\hline Malaysia & 0.1 & 0.2 & 0.2 & 0.4 & 0.2 & 0.4 & 0.1 & 0.2 & 0.0 & 0.0 & 0.0 & 0.0 & 1.4 & 3.4 & 0.4 & 1.2 & 0.0 & -0.1 \\
\hline Thailand & 0.4 & 0.7 & -0.9 & -3.3 & 28.0 & 92.3 & -0.7 & -3.0 & 0.0 & 0.0 & 0.4 & 1.7 & -0.3 & -2.1 & -0.5 & -2.8 & -0.5 & -2.2 \\
\hline Rest of East Asia \& Pacific & 0.1 & 0.2 & 0.0 & -0.1 & 3.2 & 8.3 & 0.1 & 0.2 & 0.4 & 1.5 & 0.9 & 3.7 & 0.6 & 1.6 & 0.3 & 1.0 & 0.0 & -0.1 \\
\hline India & 0.2 & 0.3 & -0.7 & -0.6 & 13.3 & 13.5 & -1.0 & -0.9 & -0.4 & -0.3 & -0.4 & -0.3 & -0.4 & -0.4 & -0.6 & -0.5 & -0.6 & -0.5 \\
\hline Rest of South Asia & 0.1 & 0.2 & 0.0 & -0.1 & 0.9 & 3.2 & 0.0 & 0.1 & 0.3 & 0.8 & 0.2 & 0.8 & 0.3 & 0.5 & 1.0 & 2.9 & 0.0 & -0.1 \\
\hline Argentina & 0.4 & 0.9 & 0.6 & 0.7 & -0.1 & -0.7 & 0.1 & 0.0 & 0.5 & 1.1 & 1.5 & 5.6 & 0.3 & 0.7 & 0.5 & 1.2 & -0.2 & -0.7 \\
\hline Brazil & 0.3 & 1.1 & -1.2 & -2.0 & 17.9 & 22.3 & -1.4 & -2.1 & -1.2 & -0.2 & -1.4 & -1.3 & -0.9 & -0.6 & 1.0 & 5.4 & -1.0 & -1.6 \\
\hline Rest of LAC & 0.1 & 0.4 & 0.0 & -0.2 & 0.2 & 1.1 & 0.2 & 0.3 & 0.5 & 1.6 & 0.1 & 0.6 & 0.1 & 0.2 & 1.7 & 5.2 & 0.0 & -0.2 \\
\hline Russia & 0.2 & 0.5 & 0.1 & 0.3 & 0.3 & 0.7 & 0.4 & 1.1 & 0.3 & 1.0 & 0.4 & 1.1 & 0.6 & 1.4 & 1.7 & 4.6 & 0.0 & -0.1 \\
\hline Rest of ECA & 0.3 & 0.8 & 0.1 & 0.4 & 0.5 & 1.3 & 0.3 & 0.7 & 0.7 & 2.0 & 0.7 & 2.2 & 0.8 & 2.2 & 1.9 & 4.6 & 0.1 & 0.2 \\
\hline MENA & 0.3 & 0.8 & -0.1 & -0.2 & 0.6 & 1.5 & 0.3 & 0.6 & 1.1 & 3.3 & 1.4 & 4.9 & 0.9 & 2.5 & 1.4 & 3.6 & -0.1 & -0.3 \\
\hline South Africa & 0.4 & 1.1 & 0.0 & 0.0 & 0.6 & 1.4 & 0.5 & 1.4 & 1.8 & 5.3 & 0.4 & 1.3 & 1.4 & 3.4 & 0.7 & 2.1 & 0.1 & 0.3 \\
\hline Rest of Sub-Saharan Africa & 0.1 & 0.2 & 0.0 & 0.1 & 0.3 & 0.6 & 0.2 & 0.4 & 1.0 & 3.2 & 0.0 & 0.2 & 0.0 & -0.1 & 0.2 & 0.7 & -0.2 & -0.4 \\
\hline
\end{tabular}


Table 5. Change in Agricultural Imports (\%) relative to the baseline in 2020 - by region

\begin{tabular}{|c|c|c|c|c|c|c|c|c|c|c|c|c|c|c|c|c|c|c|}
\hline \multirow[t]{2}{*}{ Country/Regions } & \multicolumn{2}{|c|}{ Agriculture } & \multicolumn{2}{|c|}{ Paddy rice } & \multicolumn{2}{|c|}{ Sugar crops } & \multicolumn{2}{|c|}{ Other crops } & \multicolumn{2}{|c|}{ Wheat } & \multicolumn{2}{|c|}{ Corn } & \multicolumn{2}{|c|}{ Other grains } & \multicolumn{2}{|c|}{ Oilseeds } & \multicolumn{2}{|c|}{ Livestock } \\
\hline & AT & ET & AT & ET & AT & ET & AT & ET & AT & ET & AT & ET & AT & ET & AT & ET & AT & ET \\
\hline World total & 1.0 & 3.0 & 0.3 & 0.7 & 1.6 & 4.2 & 0.7 & 1.8 & 0.9 & 3.0 & 1.8 & 6.9 & 4.3 & 12.1 & 4.2 & 13.2 & 0.4 & 1.1 \\
\hline High-income & 2.3 & 7.0 & 0.4 & 1.2 & 14.0 & 62.3 & 0.8 & 2.1 & 3.0 & 7.7 & 1.6 & 4.9 & 14.0 & 37.7 & 13.3 & 43.5 & 0.5 & 1.3 \\
\hline Australia and New Zealand & 0.8 & 2.3 & 0.8 & 1.9 & -0.6 & 1.6 & 0.8 & 2.2 & 2.8 & 16.3 & 1.1 & 3.8 & -0.3 & 1.0 & 1.5 & 4.4 & 0.5 & 1.2 \\
\hline Japan & 0.5 & 1.5 & 0.2 & 0.6 & -0.9 & 1.4 & -0.2 & -0.3 & 0.5 & 1.4 & 0.8 & 2.5 & 0.4 & 1.1 & 0.8 & 2.4 & -0.1 & -0.2 \\
\hline Canada & 1.3 & 4.1 & 0.5 & 1.4 & 0.5 & 1.8 & 0.8 & 2.0 & 9.3 & 36.3 & 9.1 & 34.8 & 1.7 & 6.3 & 1.4 & 4.1 & 0.6 & 1.8 \\
\hline France & 4.5 & 13.7 & 1.1 & 3.1 & 211.2 & 983.4 & 2.1 & 6.2 & 34.2 & 97.1 & 1.4 & 4.3 & -1.3 & 0.1 & 84.6 & 274.4 & 1.2 & 3.6 \\
\hline Germany & 5.0 & 19.1 & 0.5 & 1.5 & 0.0 & 2.8 & 0.7 & 2.1 & 14.6 & 41.8 & 1.4 & 4.8 & 7.9 & 23.2 & 32.3 & 126.4 & 0.4 & 1.3 \\
\hline Italy & 1.7 & 4.4 & 0.1 & 0.3 & -2.0 & -3.9 & 0.6 & 1.6 & 0.2 & 0.1 & 0.3 & 0.0 & 0.6 & 1.2 & 18.4 & 50.6 & 0.8 & 1.9 \\
\hline Spain & 2.8 & 7.5 & 0.9 & 2.4 & -0.2 & 0.1 & 0.5 & 1.2 & -0.7 & -2.1 & 0.6 & 1.4 & 43.5 & 120.6 & 1.2 & 2.5 & 0.2 & 0.4 \\
\hline UK & 2.8 & 7.5 & 0.4 & 1.1 & 19.1 & 64.5 & 1.2 & 3.0 & 4.5 & 10.7 & 1.2 & 3.5 & 133.6 & 377.8 & 20.5 & 52.8 & 1.2 & 3.0 \\
\hline Rest of EU \& EFTA & 2.7 & 6.9 & 0.3 & 0.8 & 4.5 & 14.0 & 0.6 & 1.6 & 4.5 & 10.9 & 2.3 & 5.9 & 15.5 & 39.5 & 13.2 & 34.6 & 0.4 & 1.1 \\
\hline China & 0.6 & 2.1 & 0.2 & 1.1 & -0.1 & 0.2 & 0.5 & 1.7 & 1.7 & 7.0 & 14.2 & 65.4 & 1.7 & 6.3 & 1.1 & 3.4 & 0.4 & 1.1 \\
\hline Indonesia & 1.1 & 3.7 & 1.5 & 4.0 & 67.5 & 511.0 & 0.9 & 3.0 & 0.8 & 2.0 & 0.6 & 1.4 & 0.7 & 2.1 & 2.0 & 7.4 & 0.8 & 2.5 \\
\hline Malaysia & 0.9 & 2.3 & 1.7 & 2.7 & 1.1 & 1.5 & 0.6 & 1.2 & 1.1 & 3.1 & 1.0 & 3.1 & 0.9 & 2.6 & 1.4 & 3.5 & 0.3 & 0.4 \\
\hline Thailand & 1.0 & 3.3 & 1.9 & 4.7 & 159.3 & $1,324.4$ & 1.1 & 3.4 & 0.2 & -0.1 & 2.5 & 9.5 & -0.5 & -1.0 & 1.0 & 2.4 & 0.6 & 1.4 \\
\hline Rest of East Asia \& Pacific & 0.7 & 1.8 & 0.4 & 0.6 & 15.4 & 45.8 & 0.7 & 1.6 & 0.8 & 2.3 & 0.9 & 2.9 & 0.2 & 0.5 & 0.9 & 2.6 & 0.3 & 0.7 \\
\hline India & 3.9 & 4.6 & 6.8 & 7.8 & 173.6 & 171.1 & 4.3 & 5.0 & 6.2 & 2.3 & 6.4 & 2.8 & 5.1 & 0.7 & 6.1 & 4.8 & 2.1 & 3.2 \\
\hline Rest of South Asia & 0.4 & 0.7 & 0.3 & -0.5 & 4.4 & 16.7 & 0.5 & 0.9 & 0.0 & -0.6 & 0.4 & 0.8 & 0.0 & -0.4 & 0.6 & 1.1 & 0.2 & -0.1 \\
\hline Argentina & 0.7 & 2.3 & -1.8 & -3.5 & 0.3 & 0.7 & 0.4 & 1.6 & 0.0 & 0.8 & 9.6 & 40.9 & 0.1 & 1.5 & 0.8 & 2.1 & 0.5 & 0.6 \\
\hline Brazil & 1.2 & 2.7 & 1.9 & 3.5 & 0.0 & 0.0 & 1.8 & 3.4 & 0.3 & 1.6 & 1.9 & 3.5 & 1.3 & 2.1 & 3.8 & 10.0 & 1.2 & 1.9 \\
\hline Rest of LAC & 0.6 & 1.6 & 0.5 & 1.2 & 0.5 & 3.4 & 0.6 & 1.7 & 0.4 & 1.0 & 0.3 & 0.4 & 0.3 & 0.8 & 1.3 & 3.8 & 0.3 & 0.8 \\
\hline Russia & -0.6 & -1.4 & -0.5 & -1.5 & -2.1 & -5.7 & -0.1 & -0.3 & -1.4 & -3.4 & -0.9 & -2.6 & -3.6 & -9.4 & -1.5 & -4.4 & -1.1 & -2.6 \\
\hline Rest of ECA & 0.0 & -0.2 & 0.1 & 0.1 & -1.9 & -5.2 & 0.4 & 0.8 & -1.5 & -4.0 & -0.5 & -1.6 & -3.8 & -8.7 & 0.6 & 1.0 & 0.2 & 0.4 \\
\hline Rest of Sub-Saharan Africa & -0.1 & -0.4 & -0.2 & -0.7 & -0.5 & -1.6 & -0.2 & -0.6 & 0.6 & 1.7 & -0.7 & -2.2 & -2.8 & -6.3 & -1.2 & -3.4 & -0.5 & -1.1 \\
\hline
\end{tabular}


Table 6. Change in Agricultural Exports (\%) relative to the baseline in 2020 - by region

\begin{tabular}{|c|c|c|c|c|c|c|c|c|c|c|c|c|c|c|c|c|c|c|}
\hline \multirow[t]{2}{*}{ Country/Regions } & \multicolumn{2}{|c|}{ Agriculture } & \multicolumn{2}{|c|}{ Paddy rice } & \multicolumn{2}{|c|}{ Sugar crops } & \multicolumn{2}{|c|}{ Other crops } & \multicolumn{2}{|c|}{ Wheat } & \multicolumn{2}{|c|}{ Corn } & \multicolumn{2}{|c|}{ Other grains } & \multicolumn{2}{|c|}{ Oilseeds } & \multicolumn{2}{|c|}{ Livestock } \\
\hline & AT & ET & AT & ET & AT & ET & AT & ET & AT & ET & AT & ET & AT & ET & AT & ET & AT & ET \\
\hline World total & 1.0 & 3.0 & 0.3 & 0.7 & 1.6 & 4.2 & 0.7 & 1.8 & 0.9 & 3.0 & 1.8 & 6.9 & 4.3 & 12.1 & 4.2 & 13.2 & 0.4 & 1.1 \\
\hline High-income & 0.9 & 2.5 & 0.7 & 1.7 & -2.6 & -5.6 & 0.6 & 1.4 & 0.7 & 2.2 & 2.0 & 7.2 & 4.2 & 11.7 & 4.3 & 12.8 & 0.4 & 1.0 \\
\hline Australia and New Zealand & 1.0 & 2.6 & 0.6 & 1.4 & 2.9 & 4.5 & 1.0 & 2.5 & 1.6 & 4.5 & 7.1 & 30.4 & 2.0 & 6.1 & 3.2 & 8.9 & 0.6 & 1.6 \\
\hline Japan & 2.0 & 5.5 & 2.5 & 7.1 & 4.7 & 9.3 & 2.4 & 6.4 & 3.4 & 10.8 & 1.0 & 4.1 & 2.9 & 5.8 & 5.6 & 16.3 & 1.4 & 4.0 \\
\hline Canada & 1.0 & 2.6 & 0.0 & 0.0 & 2.0 & 4.3 & 0.8 & 1.1 & 1.4 & 4.3 & 4.0 & 17.5 & 2.1 & 5.9 & 2.5 & 7.1 & 0.3 & 0.8 \\
\hline France & 0.5 & 0.8 & -1.6 & -4.9 & -44.1 & -67.4 & -1.9 & -6.7 & -1.3 & -4.5 & 1.4 & 4.2 & 13.9 & 35.5 & 13.0 & 40.1 & -0.9 & -3.1 \\
\hline Germany & 1.1 & 1.9 & 0.0 & 0.0 & 6.1 & 13.3 & 0.5 & 0.4 & 0.3 & -1.1 & 4.3 & 16.4 & 10.9 & 27.2 & 4.1 & 1.8 & 0.5 & 1.0 \\
\hline Italy & 1.0 & 2.6 & 1.1 & 2.7 & 4.6 & 12.6 & 1.2 & 2.9 & 4.1 & 12.3 & 2.7 & 10.0 & 5.6 & 14.7 & 9.7 & 28.5 & 0.2 & 0.3 \\
\hline Spain & 1.2 & 3.2 & 0.3 & 0.8 & 39.7 & 184.9 & 0.9 & 2.4 & 6.0 & 18.7 & 5.8 & 23.9 & 7.2 & 18.2 & 13.8 & 43.5 & 0.8 & 1.7 \\
\hline UK & -1.1 & -2.0 & 0.0 & 0.0 & -28.8 & -58.6 & -0.9 & -2.6 & -1.3 & -0.3 & 0.0 & 0.0 & -25.1 & -44.0 & 11.6 & 41.5 & -1.0 & -2.6 \\
\hline Rest of EU \& EFTA & 0.6 & 1.8 & 1.0 & 2.7 & -1.3 & -3.7 & 0.8 & 2.1 & -1.4 & -2.4 & -1.5 & -1.1 & 1.3 & 4.9 & 6.2 & 21.0 & 0.2 & 0.7 \\
\hline China & 1.0 & 1.0 & 0.6 & 0.5 & 8.2 & 17.9 & 1.3 & 1.8 & 0.6 & -1.3 & -12.0 & -40.5 & 0.0 & -4.8 & 3.1 & 5.7 & 0.6 & 0.6 \\
\hline Indonesia & 0.3 & -0.9 & 0.3 & -0.7 & -52.0 & -92.9 & 0.4 & -0.9 & 0.0 & 0.0 & 9.2 & 41.6 & 0.0 & 0.0 & 2.7 & 0.8 & -0.3 & -1.5 \\
\hline Malaysia & 1.0 & 3.0 & -0.6 & -1.1 & 1.2 & 5.3 & 1.2 & 3.3 & 0.0 & 0.0 & 0.0 & 0.0 & 2.1 & 5.4 & 3.0 & 8.2 & 0.6 & 2.0 \\
\hline Thailand & -0.1 & -1.4 & -1.9 & -6.4 & -69.8 & -96.7 & -0.1 & -1.6 & 0.0 & 0.0 & 3.0 & 11.8 & -0.1 & -1.6 & 0.5 & -0.1 & -0.2 & -1.5 \\
\hline Rest of East Asia \& Pacific & 1.4 & 3.8 & 1.1 & 3.3 & -16.4 & -37.7 & 1.3 & 3.1 & 2.0 & 6.6 & 9.9 & 44.1 & 4.2 & 12.2 & 3.1 & 9.1 & 0.7 & 2.3 \\
\hline India & -6.0 & -1.7 & -5.7 & -4.7 & -79.7 & -78.4 & -6.3 & -4.6 & -5.9 & 3.6 & -6.9 & 11.1 & -8.8 & -0.8 & -2.4 & 3.4 & -2.8 & -2.6 \\
\hline Rest of South Asia & 2.7 & 5.1 & 1.5 & 5.0 & 11.9 & -0.9 & 2.7 & 5.0 & 3.8 & 10.6 & 6.3 & 28.0 & 8.9 & 14.0 & 3.6 & 7.0 & 1.4 & 3.6 \\
\hline Argentina & 1.5 & 4.0 & 4.2 & 8.0 & 0.8 & 2.9 & 1.0 & 2.5 & 1.4 & 3.9 & -0.1 & -1.7 & 3.9 & 10.0 & 2.5 & 7.3 & 0.1 & 0.9 \\
\hline Brazil & 0.5 & 4.8 & -2.0 & -1.6 & -50.0 & -57.6 & -1.9 & -2.0 & 1.1 & 6.5 & -1.1 & 1.5 & 2.8 & 13.2 & 4.1 & 15.1 & -2.0 & -1.8 \\
\hline Rest of LAC & 1.4 & 3.8 & 0.8 & 1.9 & 2.8 & 3.7 & 1.1 & 2.7 & 3.4 & 10.5 & 5.3 & 21.7 & 5.6 & 16.4 & 5.9 & 18.4 & 0.6 & 1.8 \\
\hline Russia & 3.7 & 10.1 & 2.3 & 6.0 & 0.0 & 0.0 & 2.9 & 7.6 & 7.5 & 22.3 & 8.5 & 31.3 & 8.4 & 23.7 & 13.0 & 35.5 & 2.9 & 7.6 \\
\hline Rest of ECA & 1.7 & 4.5 & 1.2 & 3.3 & 5.4 & 14.5 & 1.3 & 3.6 & 2.7 & 8.3 & 2.8 & 10.5 & 5.6 & 16.0 & 7.4 & 17.3 & 0.8 & 2.4 \\
\hline Rest of Sub-Saharan Africa & 2.2 & 5.4 & 1.7 & 4.9 & 6.1 & 16.8 & 2.1 & 4.8 & 3.5 & 10.9 & 5.8 & 25.1 & 7.3 & 20.2 & 4.9 & 13.5 & 1.7 & 4.5 \\
\hline
\end{tabular}


Table 7. Change in world prices and multipliers (100\%\% price change/\% world biofuel output change)

\begin{tabular}{|c|c|c|c|c|}
\hline & $\begin{array}{c}\mathrm{AT} \% \text { price } \\
\text { change }\end{array}$ & $\begin{array}{l}\text { ET \% price } \\
\text { change }\end{array}$ & $\begin{array}{c}\text { AT } \\
\text { multiplier }\end{array}$ & $\begin{array}{c}\text { ET } \\
\text { Multiplier } \\
\end{array}$ \\
\hline Sugar (cane \& beet) & 9.2 & 11.6 & $22.3 \%$ & $12.3 \%$ \\
\hline Ethanol & 2.8 & 4.6 & $6.9 \%$ & $4.9 \%$ \\
\hline Biofuels & 2.7 & 4.5 & $6.5 \%$ & $4.8 \%$ \\
\hline Agriculture & 2.2 & 3.8 & $5.5 \%$ & $4.0 \%$ \\
\hline Corn & 1.1 & 3.7 & $2.7 \%$ & $3.9 \%$ \\
\hline Biodiesel & 1.1 & 3.3 & $2.7 \%$ & $3.5 \%$ \\
\hline Oilseeds & 1.5 & 3.1 & $3.7 \%$ & $3.3 \%$ \\
\hline Wheat & 1.1 & 2.4 & $2.8 \%$ & $2.6 \%$ \\
\hline Other cereal grains & 1.0 & 2.3 & $2.5 \%$ & $2.5 \%$ \\
\hline Paddy rice & 0.8 & 1.6 & $2.0 \%$ & $1.7 \%$ \\
\hline Vegetables, fruit & 0.7 & 1.5 & $1.6 \%$ & $1.6 \%$ \\
\hline Livestock & 0.4 & 1.1 & $1.0 \%$ & $1.1 \%$ \\
\hline Forestry & 0.3 & 0.9 & $0.8 \%$ & $0.9 \%$ \\
\hline All goods and services & 0.5 & 0.8 & $1.3 \%$ & $0.8 \%$ \\
\hline Processed food & 0.2 & 0.5 & $0.5 \%$ & $0.5 \%$ \\
\hline Other services & 0.0 & 0.0 & $0.0 \%$ & $0.0 \%$ \\
\hline Other manufacturing & 0.0 & 0.0 & $0.0 \%$ & $0.0 \%$ \\
\hline Construction & 0.0 & 0.0 & $0.0 \%$ & $0.0 \%$ \\
\hline Other mining & 0.0 & -0.1 & $0.0 \%$ & $-0.1 \%$ \\
\hline Coal & 0.0 & -0.1 & $-0.1 \%$ & $-0.1 \%$ \\
\hline Gas distribution & -0.1 & -0.1 & $-0.2 \%$ & $-0.1 \%$ \\
\hline Chemicals & -0.1 & -0.1 & $-0.1 \%$ & $-0.1 \%$ \\
\hline Electricity & -0.1 & -0.2 & $-0.2 \%$ & $-0.2 \%$ \\
\hline Total Industry and services & -0.2 & -0.4 & $-0.4 \%$ & $-0.4 \%$ \\
\hline Natural gas & -0.2 & -0.4 & $-0.5 \%$ & $-0.4 \%$ \\
\hline Transport services & -0.2 & -0.6 & $-0.6 \%$ & $-0.6 \%$ \\
\hline Other industrial sectors and services & -0.3 & -0.6 & $-0.7 \%$ & $-0.7 \%$ \\
\hline Diesel & -0.6 & -1.4 & $-1.5 \%$ & $-1.4 \%$ \\
\hline Gasoline & -0.6 & -1.4 & $-1.5 \%$ & $-1.5 \%$ \\
\hline Refined oil & -0.6 & -1.4 & $-1.5 \%$ & $-1.5 \%$ \\
\hline Crude oil & -0.8 & -1.7 & $-1.9 \%$ & $-1.8 \%$ \\
\hline
\end{tabular}

In Brazil, the loss of forest relative to the baseline amounted to 6.1 million hectares in 2020 , which is the largest change generated in physical terms; it represents 1.2\% of Brazil's total forest area in 
$2020^{6}$. As shown in Table 8, within the crop allocations, large changes take place within many countries, with massive land reallocation away from rice and other crops to sugar crops, coarse grains and corn. The implementation of the ET to 2020 increases land use in crops globally. In the longer run, technical progress would take place and productivity gains would reduce the ramping up of land use. Under the ET scenario, worldwide land devoted to sugar and other coarse grains increases by $9.4 \%$ and $6.9 \%$ respectively. The impacts on land-use in Al-Riffai el al. (2010) and Fischer et al. (2009) are close to ours. Within croplands, like in our study, land for sugar crops would increase the most followed by land for rapeseed. They also find that land for rice and vegetable and fruit would decline due to the expansion of biofuels to meet the existing targets. Fischer et al. (2009) find that expansion of biofuels to meet the targets could increase total arable land by 1 to $3 \%$, depending upon the scenarios, in 2020.

Figure 2. Change in forest land (Million hectares) relative to the baseline in 2020

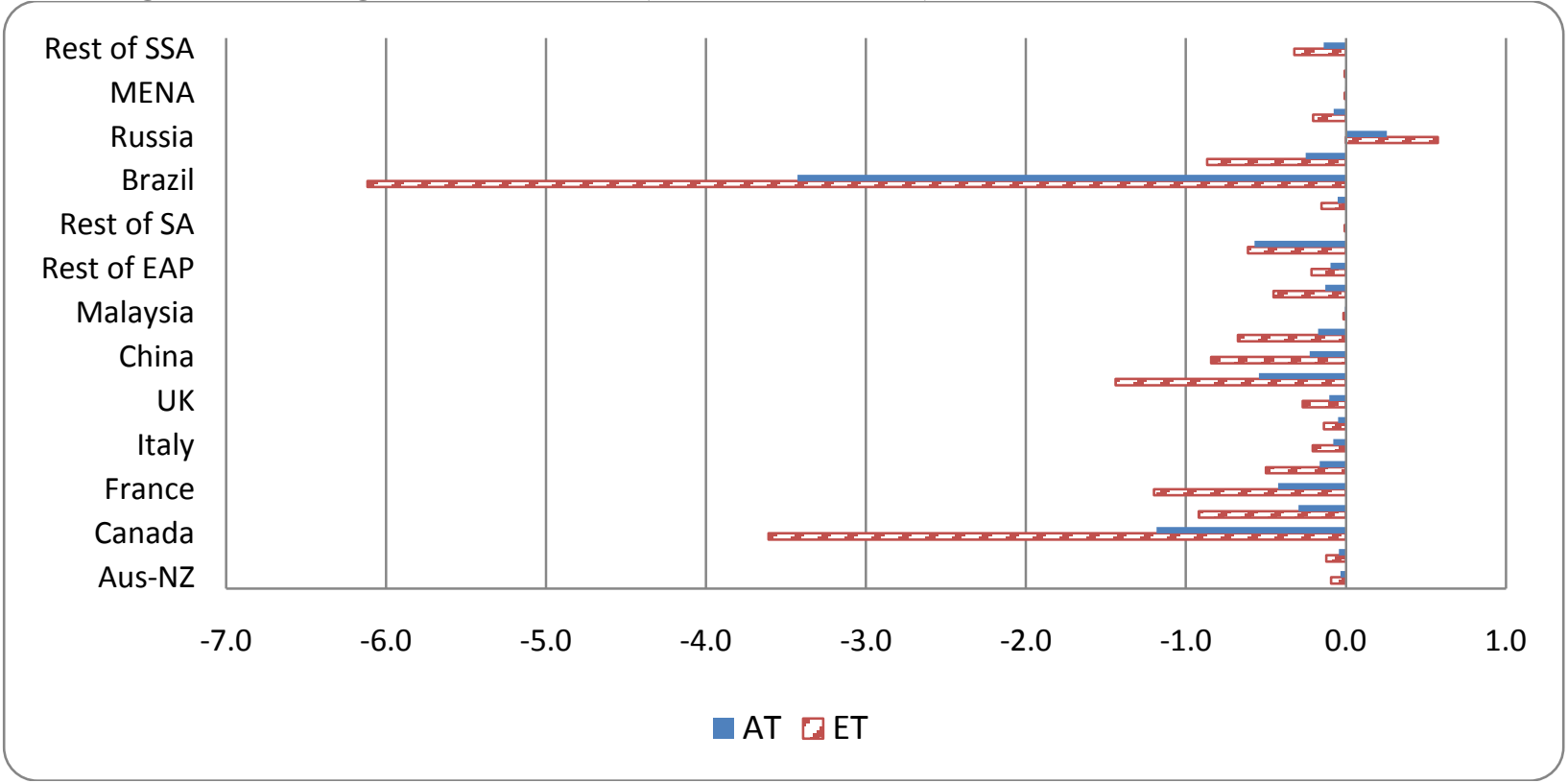

\section{Impacts on food supply}

Food supply includes direct consumption of crops, fruits and vegetables, and livestock, and

\footnotetext{
${ }^{6}$ A general equilibrium study by Fischer et al. (2009) finds that expansion of biofuels could cause up to 20 million hectares of deforestation by 2020.
} 
processed food. The composition of the food supply changes however, since the shares of livestock products, sugar, and some grains decrease the most. This global effect does not exclude stronger localized effects when feedstock and food use directly compete locally and with costly transportation. Nevertheless regional trade within a country should help dampen these potential effects. If biofuels are produced locally, trade costs must have been reduced for all commodities and arbitrage in food markets would take place if local commodity prices rise significantly.

In 2020 , under the ET scenario, world food supply decreases by $\$ 14.1$ billion or $0.2 \%$ from the corresponding food supply in the baseline. Under the AT scenario, the reduction in food supply is about half as large. Note that the percentage reduction in food supply is estimated to be negligible, particularly in a dynamic context. This is due to a large base as we include the entire food sector, including cereals, processed food and livestock. Considering only cereals, Fischer et al. (2009) show that expansion of biofuels to meet the existing targets would cause a reduction in a range of 8-29 million tons of food supply in 2020 relative to its reference case. In the reference case, they projected that the total consumption of cereals in year 2020 to be 2,775 million tons. Hence, the reduction of food supply would be $0.29 \%$ to $1.05 \%$ relative to the base case. There are several reasons for the different results. The most important among them is that Fischer et al. fixed the penetration biofuels in year 2020 at the level of 2008 in the reference case, whereas our model allows the penetration of biofuels to increase due to existing fiscal incentives.

Although the effects seem marginal at the global level, especially in percent terms, it is important to note that low and middle-income countries are more negatively affected than highincome countries. About two-third of the world food supply decrease is imputable to developing countries. Lower income economies generally rely largely on agriculture and therefore are significantly dependent on food products. China, Rest of Sub-Saharan Africa, MENA, and India would suffer the most if biofuel targets are actually implemented. Food availability would be reduced 
by $\$ 1.4$ billion in India alone under AT scenario. The United States would carry most of the burden among developed economies (see Table 9).

\section{Aggregate economic impacts}

Finally beyond, effects on land, food production and prices, it is also interesting to gauge the overall effect of a large biofuel expansion on the overall economy of various countries/regions. Figure 3 presents the impacts of biofuel expansion on countries' GDP for both scenarios. The expansion of biofuels is found to decrease global GDP $(0.02 \%$ and $0.06 \%$ reductions under AT and ET scenarios, respectively in year 2020 as compared to the baseline). At country/regional level, results are mixed. Brazil, Argentina, Thailand, Indonesia, experience increases in GDP, whereas countries like the United States, China, India experience reductions in their GDP. Countries, which have small penetration in the baseline but have set ambitious targets, would face GDP decreases because the targets significant alter the allocation of resources in production and change trade patterns, resulting in a worsening of the terms of trade. India is a good example, where the government has set a target of $20 \%$ (or $17 \%$ in terms of energy content) for biofuels by 2020 , but its current level of biofuels use is small. Achieving this target would cause India's imports of agricultural commodities, to increase, in aggregate, by 3.9 to $4.6 \%$ depending on the scenarios (see Table 5). ${ }^{7}$

Its export would drop by 1.7 to $6 \%$. The terms of trade deteriorates thereby causing significant GDP loss (0.13\% to 0.23\%). Countries like Brazil, Argentina and Indonesia would experience increases in their GDP due to increased exports of biofuels or feedstock required for biofuels. These countries experience improvements of their terms of trade. Energy exporting countries/regions, such as MENA and Russia will face reductions in GDP due to decreases in their oil exports thereby causing negative terms of trade effects.

\footnotetext{
${ }^{7}$ Note that India has different impacts on different scenarios although the targets are the same for both. This is because the effects of international trade would be different between these two scenarios.
} 
Table 8. Changes in land supply (\%) relative to the baseline in 2020

\begin{tabular}{|c|c|c|c|c|c|c|c|c|c|c|c|c|c|c|c|c|c|c|c|c|}
\hline \multirow[t]{2}{*}{ Country/Regions } & \multicolumn{2}{|c|}{ Total crop } & \multicolumn{2}{|c|}{ Forest } & \multicolumn{2}{|c|}{ Pasture } & \multicolumn{2}{|c|}{ Rice } & \multicolumn{2}{|c|}{ Sugar crops } & \multicolumn{2}{|c|}{ Other crops } & \multicolumn{2}{|c|}{ Wheat } & \multicolumn{2}{|c|}{ Corn } & \multicolumn{2}{|c|}{ Other grains } & \multicolumn{2}{|c|}{ Oilseeds } \\
\hline & AT & ET & AT & ET & AT & ET & AT & ET & AT & ET & AT & ET & AT & ET & AT & ET & AT & ET & AT & ET \\
\hline World total & 0.1 & 0.2 & -0.2 & -0.6 & -0.2 & -0.5 & -0.3 & -0.6 & 6.4 & 9.4 & -0.5 & -1.2 & 0.0 & 0.4 & 0.3 & 1.7 & 3.1 & 6.9 & 0.6 & 2.2 \\
\hline High-income & 0.1 & 0.4 & -0.4 & -1.1 & -0.3 & -0.8 & -0.2 & -0.6 & 6.3 & 12.8 & -0.7 & -2.1 & 0.4 & 1.0 & -0.2 & -0.1 & 7.8 & 17.0 & 3.0 & 8.0 \\
\hline Australia and New Zealand & 0.1 & 0.2 & -0.1 & -0.2 & 0.0 & -0.1 & -0.1 & -0.4 & 0.0 & 0.6 & 0.0 & -0.2 & 0.5 & 1.7 & 0.6 & 2.7 & 0.4 & 1.1 & 1.2 & 3.2 \\
\hline Japan & 0.0 & 0.0 & -0.1 & -0.3 & 0.0 & -0.1 & -0.2 & -0.6 & 0.1 & 1.3 & 0.0 & 0.0 & 0.4 & 1.3 & 0.0 & 0.7 & 0.5 & 1.5 & 0.3 & 1.1 \\
\hline Canada & 0.1 & 0.4 & -0.2 & -0.5 & -0.2 & -0.6 & 0.0 & 0.0 & -0.2 & -0.6 & -0.3 & -1.3 & 0.0 & 0.3 & 2.7 & 10.2 & 0.2 & 0.5 & 0.4 & 0.9 \\
\hline United States & 0.0 & 0.1 & -0.1 & -0.3 & -0.1 & -0.2 & -0.1 & -0.4 & -0.1 & -0.4 & -0.1 & -0.4 & 0.5 & 1.7 & 0.3 & 1.4 & 0.3 & 0.5 & 0.5 & 1.3 \\
\hline France & 0.3 & 0.7 & -1.8 & -5.1 & -1.4 & -4.1 & -3.2 & -8.9 & 37.0 & 73.0 & -2.8 & -7.9 & 0.8 & 0.7 & -2.8 & -7.5 & 3.1 & 5.8 & 17.3 & 46.0 \\
\hline Germany & 0.3 & 0.8 & -0.7 & -2.2 & -0.5 & -1.5 & 0.0 & 0.0 & -0.4 & -0.8 & -0.9 & -3.0 & 3.3 & 7.3 & -0.8 & -1.0 & 3.9 & 8.7 & 11.0 & 33.6 \\
\hline Italy & 0.2 & 0.4 & -0.7 & -1.9 & -0.5 & -1.3 & -0.7 & -2.0 & -0.8 & -2.0 & -0.8 & -2.1 & -0.4 & -0.6 & -1.4 & -3.3 & -0.4 & -0.8 & 8.6 & 20.7 \\
\hline Spain & 0.1 & 0.4 & -0.7 & -1.8 & -0.5 & -1.3 & -1.0 & -2.7 & -0.6 & -1.3 & -0.8 & -2.2 & -0.1 & 0.2 & -1.1 & -1.9 & 25.4 & 58.9 & 0.5 & 1.3 \\
\hline UK & 0.4 & 1.0 & -1.2 & -3.1 & -1.2 & -3.0 & 0.0 & 0.0 & 10.8 & 24.6 & -2.1 & -5.3 & -4.3 & -9.3 & 0.0 & 0.0 & 40.0 & 76.8 & 4.9 & 13.1 \\
\hline Rest of EU \& EFTA & 0.2 & 0.5 & -0.3 & -0.8 & -0.3 & -0.8 & -0.3 & -0.8 & 1.4 & 3.5 & -0.5 & -1.3 & 0.7 & 1.8 & -1.4 & -3.1 & 6.2 & 14.9 & 5.0 & 13.1 \\
\hline Middle \& Low-income & 0.1 & 0.2 & -0.1 & -0.2 & -0.2 & -0.4 & $\begin{array}{l}-0.3 \\
-0.3\end{array}$ & -0.6 & 6.5 & 8.3 & -0.3 & -0.6 & -0.3 & -0.1 & 0.7 & 3.0 & -0.1 & -0.1 & -0.3 & -0.1 \\
\hline China & 0.1 & 0.3 & -0.1 & -0.2 & -0.1 & -0.3 & -0.1 & -0.5 & 0.0 & -0.1 & -0.2 & -0.8 & 0.4 & 0.7 & 3.3 & 12.1 & -0.7 & -3.6 & -0.6 & -2.6 \\
\hline Indonesia & 0.0 & 0.1 & -0.1 & -0.4 & -0.1 & -0.4 & -0.1 & -0.7 & 6.3 & 22.8 & -0.2 & -0.9 & 0.0 & 0.0 & -0.1 & -0.4 & 0.0 & 0.0 & 0.0 & 0.1 \\
\hline Malaysia & 0.1 & 0.2 & 0.0 & 0.0 & 0.0 & -0.1 & 0.1 & 0.2 & 0.1 & 0.2 & 0.0 & 0.0 & 0.0 & 0.0 & 0.0 & 0.0 & 1.1 & 2.8 & 0.2 & 0.8 \\
\hline Thailand & 0.0 & 0.1 & -0.3 & -1.1 & -0.3 & -1.2 & -0.7 & -2.6 & 15.2 & 44.8 & -0.6 & -2.5 & 0.0 & 0.0 & 0.2 & 0.8 & -0.3 & -2.1 & -0.6 & -2.8 \\
\hline Rest of East Asia \& Pacific & 0.0 & 0.0 & 0.0 & -0.1 & -0.1 & -0.1 & -0.1 & -0.2 & 2.2 & 5.9 & 0.0 & 0.0 & 0.2 & 0.9 & 0.7 & 2.7 & 0.3 & 0.9 & 0.2 & 0.5 \\
\hline India & 0.2 & 0.2 & -0.5 & -0.6 & -0.5 & -0.5 & -0.9 & -0.9 & 10.0 & 10.0 & -1.1 & -1.1 & -0.7 & -0.8 & -0.7 & -0.6 & -0.6 & -0.7 & -0.8 & -0.8 \\
\hline Rest of South Asia & 0.0 & 0.1 & 0.0 & 0.0 & 0.0 & -0.1 & 0.0 & -0.2 & 0.6 & 2.3 & 0.0 & -0.1 & 0.1 & 0.4 & 0.1 & 0.4 & 0.1 & 0.1 & 0.8 & 2.2 \\
\hline Argentina & 0.1 & 0.2 & -0.2 & -0.5 & -0.2 & -0.6 & 0.0 & -0.6 & -0.4 & -1.2 & -0.2 & -0.6 & 0.0 & -0.1 & 0.8 & 3.4 & -0.2 & -0.5 & 0.0 & -0.1 \\
\hline Brazil & 0.2 & 0.3 & -0.7 & -1.2 & -0.7 & -1.4 & -1.1 & -2.2 & 10.7 & 12.8 & -1.3 & -2.3 & -1.3 & -1.6 & -1.5 & -2.4 & -1.1 & -1.9 & 0.4 & 2.7 \\
\hline Rest of LAC & 0.0 & 0.1 & -0.1 & -0.2 & -0.1 & -0.3 & -0.1 & -0.4 & 0.0 & 0.5 & 0.0 & -0.1 & 0.2 & 0.8 & 0.0 & 0.0 & -0.1 & -0.3 & 1.2 & 3.6 \\
\hline Russia & 0.1 & 0.3 & 0.0 & 0.0 & -0.1 & -0.3 & -0.1 & -0.3 & 0.0 & -0.1 & 0.1 & 0.2 & 0.0 & 0.0 & 0.1 & 0.2 & 0.2 & 0.5 & 1.1 & 3.0 \\
\hline Rest of ECA & 0.1 & 0.2 & -0.1 & -0.3 & -0.1 & -0.2 & -0.1 & -0.3 & 0.1 & 0.2 & 0.0 & -0.1 & 0.2 & 0.6 & 0.2 & 0.9 & 0.3 & 0.8 & 1.1 & 2.7 \\
\hline MENA & 0.1 & 0.1 & -0.2 & -0.4 & -0.1 & -0.4 & -0.2 & -0.6 & 0.2 & 0.4 & 0.0 & -0.2 & 0.5 & 1.5 & 0.7 & 2.6 & 0.3 & 0.8 & 0.7 & 1.7 \\
\hline South Africa & 0.1 & 0.3 & -0.1 & -0.2 & -0.1 & -0.2 & 0.0 & 0.0 & 0.2 & 0.3 & 0.1 & 0.2 & 1.0 & 2.9 & 0.0 & 0.1 & 0.7 & 1.7 & 0.2 & 0.7 \\
\hline Rest of Sub-Saharan Africa & 0.0 & 0.1 & 0.0 & 0.0 & -0.1 & -0.2 & 0.0 & 0.0 & 0.1 & 0.2 & 0.1 & 0.1 & 0.7 & 2.3 & -0.1 & 0.0 & -0.1 & -0.2 & 0.1 & 0.4 \\
\hline
\end{tabular}


Table 9. Change in food supply relative to the baseline in 2020 - by region

\begin{tabular}{|c|c|c|c|c|}
\hline Country/Regions & $\mathbf{A T}$ & & ET & \\
\hline & US\$ Billion & $\%$ & US\$ Billion & $\%$ \\
\hline World total & -6.5 & -0.1 & -14.1 & -0.2 \\
\hline High-income & -2.2 & -0.1 & -5.8 & -0.2 \\
\hline Australia and New Zealand & 0.0 & 0.0 & -0.1 & -0.1 \\
\hline Japan & -0.1 & 0.0 & -0.2 & -0.1 \\
\hline Canada & 0.0 & -0.1 & -0.1 & -0.2 \\
\hline United States & -0.9 & -0.1 & -2.5 & -0.3 \\
\hline France & -0.1 & 0.0 & -0.3 & -0.1 \\
\hline Germany & -0.2 & -0.1 & -0.6 & -0.2 \\
\hline Italy & -0.1 & -0.1 & -0.3 & -0.2 \\
\hline Spain & -0.1 & 0.0 & -0.2 & -0.1 \\
\hline UK & -0.2 & -0.1 & -0.4 & -0.1 \\
\hline Rest of EU \& EFTA & -0.5 & -0.1 & -1.1 & -0.2 \\
\hline Middle \& Low-income & -4.3 & -0.2 & -8.3 & -0.3 \\
\hline China & -0.5 & -0.1 & -1.3 & -0.2 \\
\hline Indonesia & -0.1 & -0.1 & -0.1 & -0.1 \\
\hline Malaysia & 0.0 & -0.1 & 0.0 & -0.3 \\
\hline Thailand & 0.0 & 0.1 & 0.0 & 0.1 \\
\hline Rest of East Asia \& Pacific & 0.0 & 0.0 & -0.2 & -0.1 \\
\hline India & -1.4 & -0.4 & -1.2 & -0.3 \\
\hline Rest of South Asia & 0.0 & 0.0 & -0.1 & -0.1 \\
\hline Argentina & 0.0 & 0.0 & 0.0 & -0.1 \\
\hline Brazil & 0.0 & 0.0 & 0.0 & 0.0 \\
\hline Rest of LAC & -0.2 & -0.1 & -0.6 & -0.3 \\
\hline Russia & -0.3 & -0.2 & -0.7 & -0.6 \\
\hline Rest of ECA & 0.0 & 0.0 & 0.0 & 0.0 \\
\hline MENA & -1.3 & -0.4 & -3.0 & -1.0 \\
\hline South Africa & 0.0 & 0.0 & 0.0 & 0.0 \\
\hline Rest of Sub-Saharan Africa & -0.5 & -0.2 & -1.2 & -0.5 \\
\hline
\end{tabular}

\section{Conclusions}

In this study we analyze the impacts of a large scale global expansion of biofuels on agriculture, land-use and food supply. The first core finding is the moderate long-term impact on commodity prices induced by a large expansion of biofuels under both scenarios. This finding is conditioned on yield gains taking place as a response to increases in commodity and land prices. In addition, and for 
both scenarios we also compute food price effects as found in recent CGE and PE analyzes which fully modeled biofuel and feedstock markets. PE analyses do not account for all sources of productivity gains and generate higher land and food price effects.

Figure 3. Change in GDP (\%) relative to the baseline in 2020 - by region

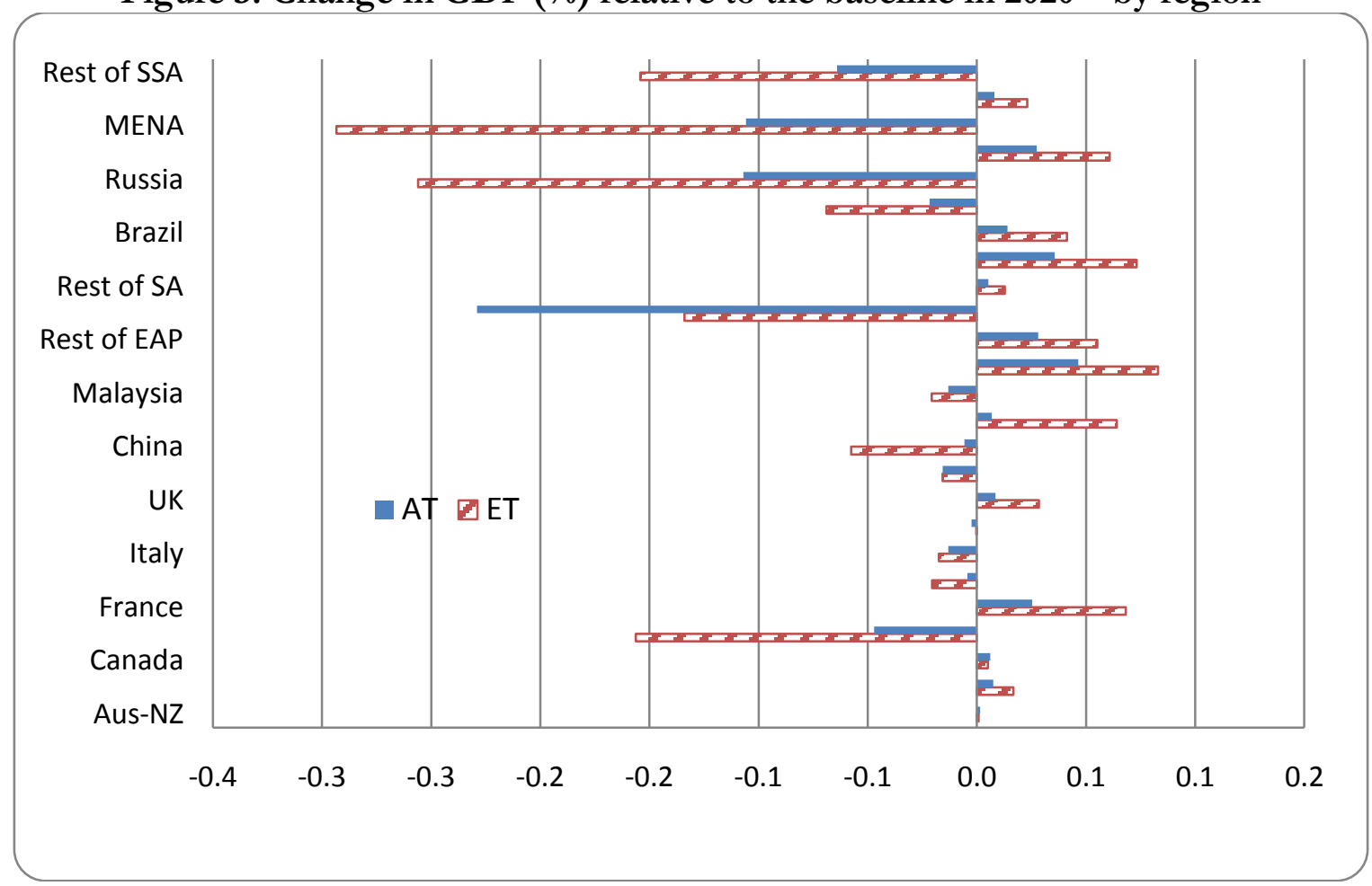

Our results suggest that planned biofuel targets would not cause large impacts on food supply at the global level although the impacts would be significant in developing countries like India and Sub-Saharan Africa. Agricultural commodities such as sugar, corn and oil seeds (as oil), that serve as the main biofuel feedstock, would experience 1\% to $9 \%$ price increases in 2020 as compared to that in the baseline due to the expansion of biofuels to meet the existing targets.

We show that land use allocation between forest, pasture and crops would be significantly altered, and leads to considerable forest and pasture destruction in several countries, especially under enhanced targets. Vast expansion of biofuel does lead to global forest losses of about 26.3 million hectares in 2020 under enhanced targets. Once targets are reached, technical progress eventually would reduce the reliance on land to expand agricultural output and forest land could be regained in 
the longer run. Within the expanded crop land uses, we obtain large effects in several countries implementing large biofuel targets. The general tendency is to expand land devoted to feedstock crops (sugar crops, coarse grains and, low quality grains for ethanol; oilseeds for vegetable oil for biodiesel). These effects are large in 2020, because they correspond with the expansion phase of the targets. In the longer run, the land expansion would recede and productivity gains would reduce the long term use of land induced in the medium term and the short term constraint on food supply would be reduced. Sugar crops and oilseeds expand the most.

We have conducted extensive sensitivity analysis. Various configurations of key parameters have been tried (elasticities of transformation in land, elasticities of substitution in production and fuel use, productivity assumptions, and trade elasticities). The qualitative results for the two scenarios are invariant to major changes in these parameters. The robustness of the results has to do first with the relative small share of farm values in food processing, hence the moderate food price effects. Second, the increase in demand for feedstock can be accommodated given the various mechanisms at play via trade in agricultural commodities, land allocation, and biofuels production, even under limited land substitution across uses. Small relative land variations can accommodate additional feedstock demand. Putting land into production takes resources and time, hence these results imply that adjustments can take place over time. Again the long-tern nature of our analysis cannot be over stated. In addition, we have considered dry distiller grains (DDGS) as a feed crop substitute. DDGS are a byproduct of ethanol and provide revenues and reduce feed grain demand. DDGS are good substitutes for coarse grains, especially corn. Accordingly the implied indirect land use and price effects linked to feed grains are dampened once DDGS are accounted for.

Considering the size and complexity of the model, we could not exactly incorporate all policy parameters which might affect the quantitative results, particularly in the enhanced scenario. Moreover, we have not accounted for existing distortions in sugar and energy markets. 


\section{References}

Al-Riffai, P., B. Dimaranan, and D. Laborde, 2010. "Global Trade and Environmental Impact Study of the EU Biofuels Mandate", Report for the European Commission, DG TRADE, ATLASS Consortium.

Banse, M., H. van Meijl, A. Tabeau, and G. Woltjer. 2008a. "Will EU biofuel policies affect global agricultural markets?” European Review of Agricultural Economics Vol 35 (2) (2008): 117-141.

Banse, M., P. Nowicki, and H. van Meijl. 2008b. "Why are current food prices so high?" in Zuurbier, P., and J. van de Vooren, eds. Sugarcane Ethanol. Contributions to climate change mitigation and the environment, 2008, Wageningen Academic Publishers, chapter 10: 227-247.

Birur, D., T.W. Hertel, and W. Tyner. 2008. "Impact of Biofuel Production on World Agricultural Markets: A Computable General Equilibrium Analysis”, GTAP Working Paper No 53, Center for Global Trade Analysis, Purdue University.

Bouët, A., L. Curran, B. Dimaranan, M-P. Ramos, and H. Valin. 2008. "Biofuels: Global Trade and Environmental Impact Study." CEPII draft report, December 17, Paris.

Chen, X., H. Huang, M. Khanna, and H. Onal. 2010. "Meeting the Mandate for Biofuels: Implications for Land Use, Greenhouse Gas Emissions and Social Welfare," Presented at the NBER Agricultural Economics Conference, March 4-5, Cambridge.

De Santi, G (2008) Biofuels in the European Context: Facts and Uncertainties, Joint Research Centre (JRC), Petten, the Netherlands.

Elobeid, A., and S. Tokgoz. 2008. Removal of U.S. Ethanol Domestic and Trade Distortions: Impact on U.S. and Brazilian Ethanol Markets." American Journal of Agricultural Economics 2008 90(4): 918-932.

Energy Information Administration (EIA). 2006. Annual Energy Outlook 2006 with Projections to 2030. Report\#: DOE/EIA-0383. http://www.eia.doe.gov/oiaf/aeo/ (accessed July 2006), February 2006.

Fabiosa, J., J. Beghin J. F. Dong, A. Elobeid, S. Tokgoz, and T-H. Yu. (2010). "Land Allocation Effects of the Global Ethanol Surge. Predictions from the International FAPRI Model." Land Economics. 86(4) 2010: 687-706

Fischer, G., E. Hizsnyik, S. Prieler, M. Shah and H. van Velthuizen. 2009. "Biofuels and Food Security," The OPEC Fund for International Development and International Institute for Applied Systems Analysis.

Gohin, A. 2008. Impacts of the European Biofuel Policy on the Farm Sector: A General Equilibrium Assessment. Review of Agricultural Economics Volume 30 Issue 4 (2008): 623 - 641.

Gurgel, A., J. M. Reilly, and S. Paltsev. 2007. "Potential Land Use Implications of a Global Biofuels Industry," Journal of Agricultural \& Food Industrial Organization Volume 5 2007, Article 9.

Hertel, T.W., D. Hummels, M. Ivanic, and R. Keeney. 2007. "How Confident Can We Be of CGE Analysis of Free Trade Agreements," Economic Modelling 24: 611-635.

Hertel, T.W., W. Tyner and D.K. Birur, 2010. “The Global Impacts of Biofuel Mandates", The Energy Journal, Vol 31 (1) (2010): 75-100.

Huang, H., F. van Tongeren, J. Dewbre, and H. van Meijl. 2004. "A New Representation of Agricultural Production Technology in GTAP” Paper Presented at the 7th Annual Conference on Global Economic Analysis, Washington DC, USA.

Keeney, R., and T.W. Hertel. 2009. "The Indirect Land Use Impacts of U.S. Biofuel Policies: The Importance of Acreage, Yield, and Bilateral Trade Responses" American Journal of Agricultural Economics 91(4): 895 - 909.

Koizumi, T. \& K. Ohga. 2007. Biofuels Policies in Asian Countries: Impact of the Expanded Biofuels Programs on World Agricultural Markets. Journal of Agricultural \& Food Industrial 
Organization 5: Article 8.

Kretschmer, B., and S. Peterson. 2008. "Integrating Bioenergy into Computable General Equilibrium Models -A Survey," Kiel Institute for the World Economy Working Paper 1473, December

Kretschmer, B., D. Narita and S. Peterson. 2009. "The economic effects of the EU biofuel target", Energy Economics Vol 31: S285-S294.

Lee, H.-L., Hertel, T. W., Sohngen, B., Ramankutty, N., and U.S. Environmental Protection Agency. 2005. GTAP Greenhouse Gases Emissions Data Base. Center for Global Trade Analysis, Purdue University, West Lafayette, IN47907, U.S.A.

Lee, H-L., T.W. Hertel, and S. Rose, and M. Avetisyan. 2008. "An Integrated Global Land Use Data Base for CGE Analysis of Climate Policy Options" Center for Global Trade Analysis, Purdue University Purdue University GTAP Working Paper No. 42.

Lubowski, R., A. Plantinga, and R. Stavins. 2006. "Land-use Change and Carbon Sinks: Econometric Estimation of the Carbon Sequestration Supply Function." Journal of Environmental Economics and Management 51: 135-152

Mitchell, D. 2008. “A Note on Rising Food Prices.” Policy Research Working Paper WPS 4682, World Bank, Washington, DC.

Mullen, J, M.K, Wohlgenant, and D.E. Farris. 1988. "Input Substitution and the Distribution of Surplus Gains from Lower US Beef Processing Costs," American Journal of Agricultural Economics 70 (1988): 245-54.

Roberts, M.J., and W. Schlenker. 2010. "The U.S. Biofuel Mandate and World Food Prices: An Econometric Analysis of the Demand and Supply of Calories," Presented at the NBER Agricultural Economics Conference March 4-5, Cambridge.

Rosegrant, M.W. 2008. "Biofuels and Grain Prices: Impacts and Policy Responses.” Testimony for the U.S. Senate Committee on Homeland Security and Governmental Affairs May 7, 2008.

Runge, C.F., and B. Senauer. 2007. "How Biofuels Could Starve the Poor," Foreign Affairs 86 (3) 2007.

Searchinger, T.D., R. Heimlich, R.A. Houghton, F. Dong, A. Elobeid, J. Fabiosa, S. Tokgoz, D. Hayes, and T. Yu. 2008. "Use of Croplands for Biofuels Increases Greenhouse Gases through Emissions from Land Use Change." Science 319(5867): 1238-1240.

Sielhorst, S., J. W. Molenaar, and D. Offermans. 2008. "Biofuels in Africa. An assessment of risks and benefits for African wetlands," Commissioned paper by Wetland International. AIDEnvironment.

Taheripour, F., D. K. Birur, T.W. Hertel, and W.E. Tyner. 2007. Introducing Liquid Biofuels into the GTAP Data Base, GTAP Research Memorandum N0 11, 2007, revised May 1, 2008.

Timmer, C.P. 2008. "Causes of High Food Prices.” ADB Economics Working Paper No. 128, October 2008.

Tokgoz, S., Elobeid, A., Fabiosa, J., Hayes, D., Babcock, B., Yu, T., Dong, F. Hart, C., and Beghin, J. 2007. "Emerging Biofuels: Outlook of Effects on U.S. Grain, Oilseed, and Livestock Markets," Center for Agricultural and Rural Development, Iowa State University, Staff Report 07-SR 101, July (Revised).

van der Mensbrugghe, D. 2008. "The ENVironmental Impact and Sustainability Applied General Equilibrium (ENVISAGE) Model," The World Bank, January 2008. Available at http://go.worldbank.org/9ALYVKJHD0

World Bank, 2009. Global Economic Prospects 2009: Commodities at the Crossroads, The World Bank, Washington, DC. 


\section{Appendix to The Impacts of Biofuels Targets on Land-Use Change and Food Supply: A Global CGE Assessment (not intended for publication)}

\section{Appendix A. A Brief Description of the CGE Model}

Like in a standard CGE model, we have modeled behavior of various economic agents: production, household, government, international trade. This section provides a brief overview of the structure of the model. We start with production sector followed by households, government and foreign sectors. Finally, we also indicate the dynamic behavior of the model.

\section{Production Sector}

\section{The basic structure}

The production side of the economy is represented by a set of nested constant elasticity of substitution (CES) functions, and, for the case of land, constant elasticity of transformation (CET) functions (see Figures A1-A3 below).

On the top level of the production tree, output is produced according to the following CES specification

where $\mathrm{X}$ is gross output, VAE is the value added and energy bundle, ND is the non-energy bundle. $\alpha^{\mathrm{VAE}}$ and $\alpha^{\mathrm{ND}}$ correspond to the share parameters for VAE and ND, respectively, and $\sigma^{\mathrm{VAEND}}$ is the elasticity of substitution between VAE and ND. $\lambda^{\mathrm{VAE}}$ and $\lambda^{\mathrm{ND}}$ are the productivity parameters that represent the state of the technology. The indices $i, r$ and t correspond to sector, country/region and time, respectively.

The endogenous driver of dynamics in the model is the vintage capital structure. This means that old and new capital jointly make up the capital stock. Each time period, new capital investments are added to the existing stock, which depreciates at a given rate. Hence, the structure of the capital stock is endogenous and dynamic. Total output can be written as the sum of outputs by vintage

where the index v stands for vintage, and 


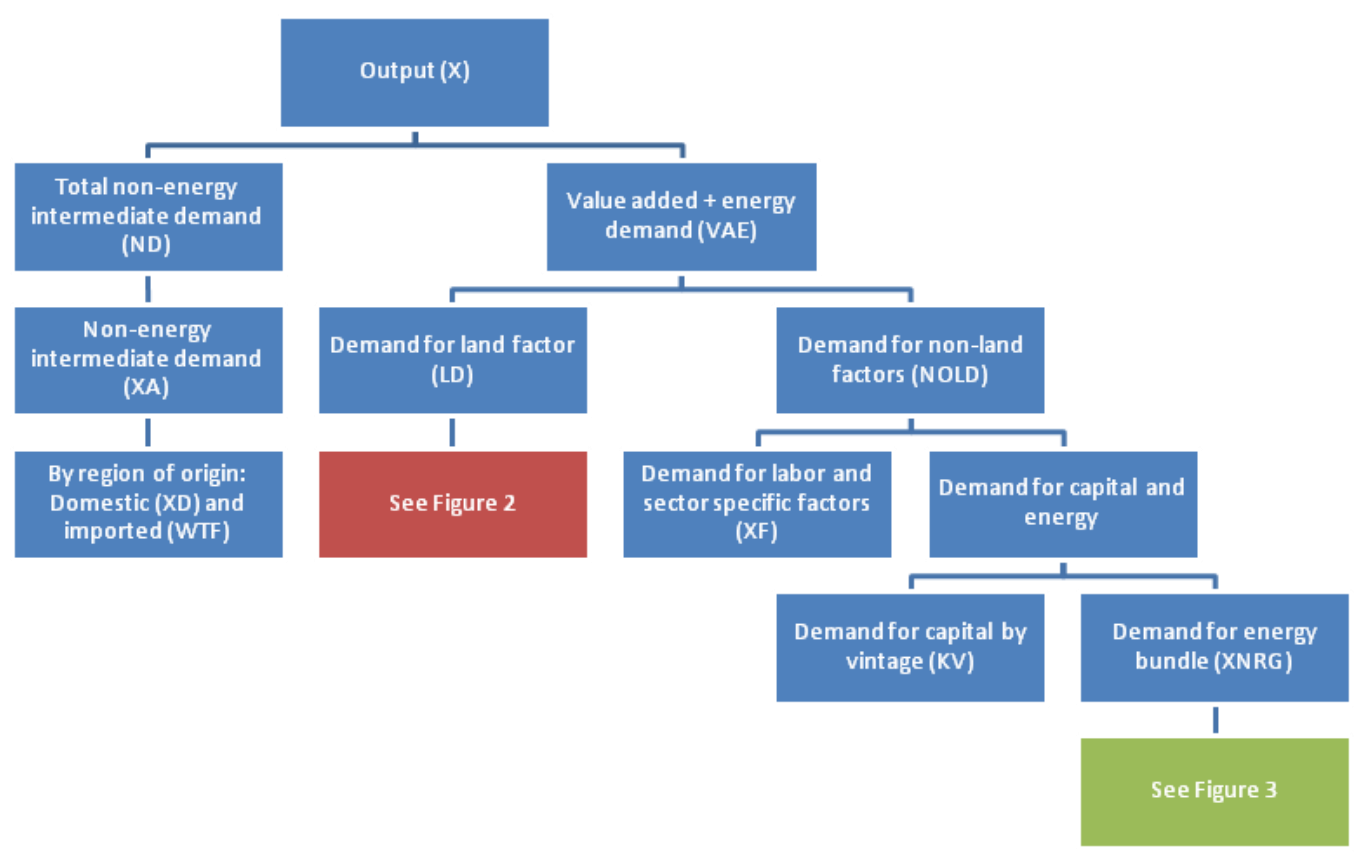

Figure A1: Structure of production sectors

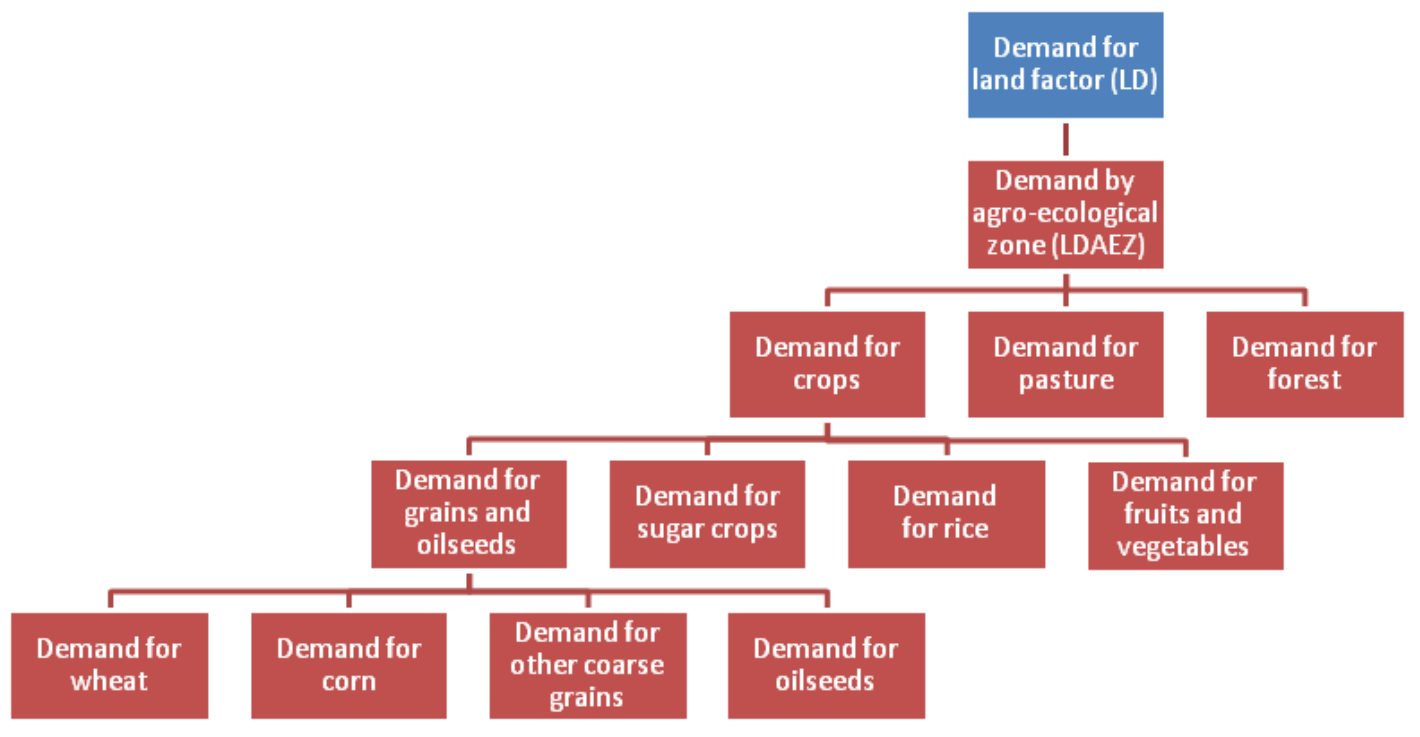

Figure A2: Structure of land use sector 


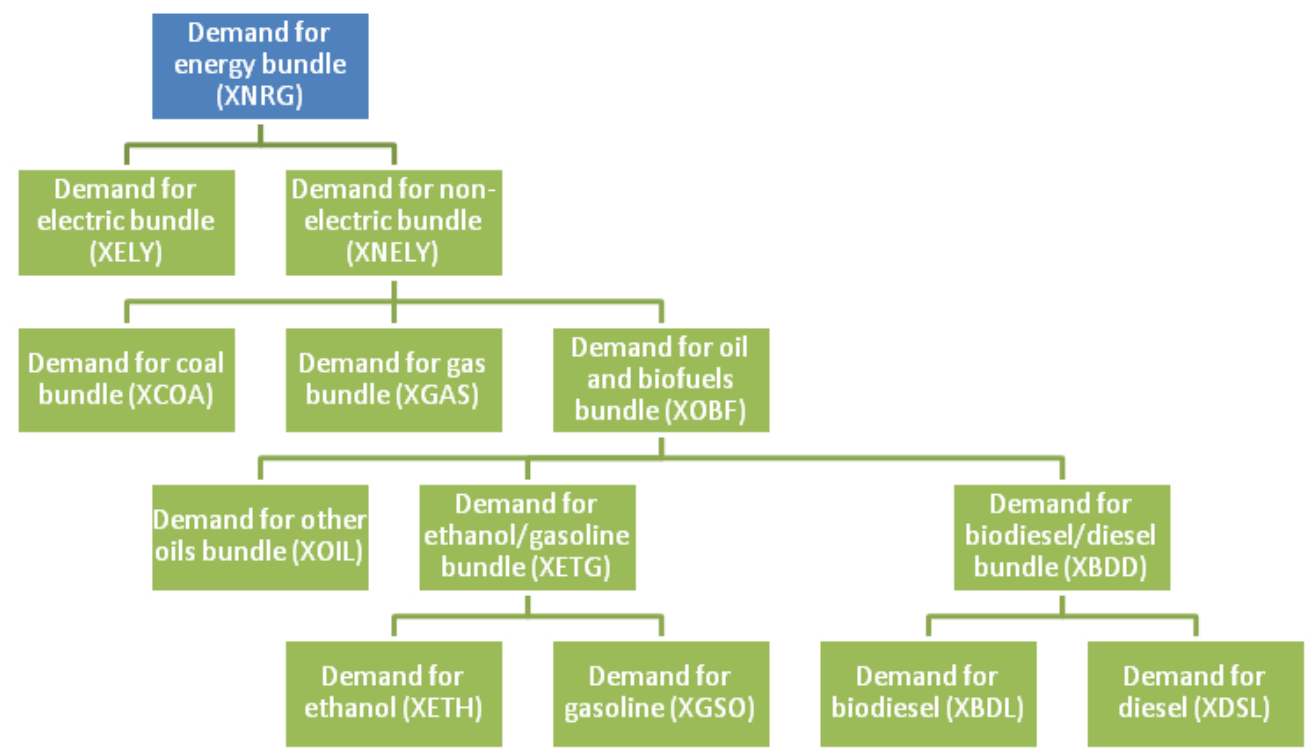

Figure A3: Structure of energy sector

Deriving input demand and unit cost functions

Producers on in the output sectors minimize costs, i.e. maximize profits, by solving the following optimization problem

where PVA and PND are the prices of VAE and ND, respectively.

The Lagrangian of the above program can be written as

where is the Lagrange coefficient on the output constraint.

Partially differentiating with respect to the input factors and yields the following first order conditions 


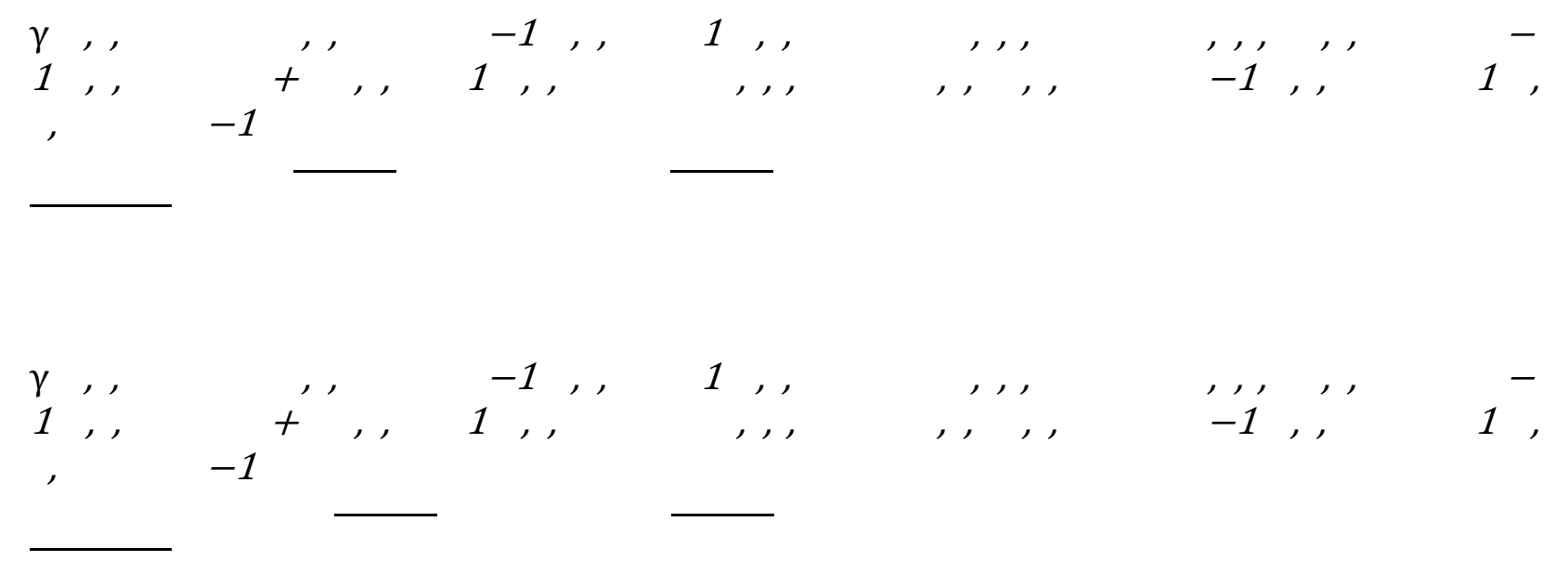

Note that, at the optimum, the coefficient corresponds to the shadow price of relaxing the output constraint marginally. This shadow price has to equal the output price as, at the cost-minimizing input combination, the cost of producing the marginal unit equals the revenue from selling this unit on the market, i.e. the output price. Hence, setting and simplifying yields the following conditional input demand functions

From the conditional factor demands we can compute the unit cost function for the output by vintage. The easiest way to do this is to substitute the solution to the firms' cost-minimization problem, i.e. the conditional factor demands (4) and (5), into the cost function, and set the required output equal to 1 . This yields

where we have set , and c corresponds to the cost of producing one unit of output.

Noting that the CES production function is linearly homogenous so that the unit cost is independent of the produced quantity, and that, in a competitive market, price equals marginal cost, . Hence, we get the price 
Finally, to calculate the unit cost (price) function for the aggregate output, we sum over all vintages and multiply by their share in total production

The input demand and unit cost functions of all the other sectors in the production tree (Figure A1 and A3) are derived analogously.

In the case of land-use module (Figure A2), total land area is divided into 18 agri-ecological zones (AEZ) according to climate types and humidity levels, and the demand for land from the various AEZs is dictated by a CES function with high elasticity of substitution. Within each AEZ, land use changes are incorporated via a nested CET representation following Huang et al. (2004) and Banse et al. (2008). In line with Birur et al. (2008), on the top level of this module, total available land area is allocated to forest land, pasture and plantation of crops. On the second level, crops are further divided into the four different categories rice, sugar-crops, fruits and vegetables, and an aggregate of grains and oilseeds. Finally, the grains and oilseeds category is partitioned into wheat, corn, other coarse grains, and oilseeds. This nested structure seems reasonable as in reality not all crops stand in direct competition. For instance, rice typically does not directly compete with other crops for available land.

In similar manner for Equations A4 and A5, all demand and price variables related to land-use module (Figure A2) are derived.

Taxes

If the government imposes taxes on the output of a product, a wedge is driven between producer price and consumer price

where PP is the price paid by the consumer on the market and and are the (ad valorem) production tax and (specific) excise tax rates, respectively. For subsidies, takes on negative values. Imperfect competition For goods that are traded on imperfectly competitive markets, a markup is added to the unit cost

where $\mathrm{m}$ corresponds to the markup.

\section{Households}

Households derive utility from the consumption of goods and services according to a constant difference of elasticities (CDE) function, which takes the following implicit form

where U corresponds to utility, PHX stands for price, UYC is per capita expenditure, and e and b 
are the expansion and substitution parameters, respectively. ${ }^{8}$ The indices $\mathrm{k}, \mathrm{r}$ and $\mathrm{h}$ denote to goods/services, region/country and household type, respectively.

From (11) we can compute the per household demand (HX) using Roy's Identity

Households save a share of their disposable income

where $\mathrm{s}$ is the savings rate and YD corresponds to the disposable income. Finally, the savings rate is determined by the following equation

where is the exogenously determines per capita growth, RAGE15 and RAGE65 are the shares of the population below 15 years and above 65 years of age.

\section{Government}

The government derives revenues from a number of indirect taxes, tariffs and a direct tax on households. These are

(i) output and excise taxes: and , respectively

(ii) sales taxes on domestic sales of Armington goods:

(iii) import tariffs on CIF price:

(iv) export taxes (or subsidies) on producer price:

(v) taxes on input factors:

(vi) emission taxes:

(vii) tax on household income:

Hence, aggregate government revenue corresponds to

where PA, PM, PE and PF are the prices of Armington goods, imports, exports and factors, respectively, BTF stands for bilateral trade flow, and is the emission coefficient per value unit. The indices $\mathrm{rr}, \mathrm{r}, \mathrm{f}$ and em denote the exporter country, importer country, factor of production and emission type, respectively. $\mathrm{YH}$ is net household income consisting of factor income and firm

\footnotetext{
${ }^{8}$ For details on the CDE form and on the interpretation of its parameters see Surry, Y. (1993). The 'constant difference of elasticities' function with applications to the EC animal feed sector, Journal of Agricultural Economics 44(1), pp. 110-125.
} 
profits minus depreciation.

Government expenditures are an exogenously determined share of nominal GDP. Government revenues equal the sum of government expenditures and government savings so that the public sector always has a balanced budget. The direct tax on household income ( ) is adjusted each period to ensure a balanced public budget.

4. Trade

The Armington demand for good XA is a CES function of domestic and imported components.

where XD and XM correspond to the domestic and foreign components of total demand, respectively, and are the share parameters, and is the elasticity of substitution between the two demand components.

Going through the same computational steps as in the cost minimization outlined in section 1, we arrive at the conditional demand functions and the price functions. The analogous derivation here corresponds to choosing the expenditure-minimizing combination of XD and XM subject to the constraint of reaching a given level of XA.

The import demand by country/region of origin corresponds to

where $\mathrm{rr}$ denotes the source of import supply, WPM is the effective export price including transport costs and any trade duties imposed by the exporter country, and is an import tariff. Aggregating the bilateral import prices over all sources yields the import price.

Export demand corresponds to

Finally, consistency requires that global net trade of homogeneous goods equals zero, i.e. global imports equal global exports for each product. 


\section{General equilibrium}

To ensure general equilibrium, a set of conditions has to be met on the global and regional levels. First, all the markets for goods and services clear, which implies that, for each country/region and commodity, the total production has to equal the sum of domestic consumption of domestically produced goods and exports.

Second, all the factor markets clear, which implies an economy-wide (for mobile factors) or sectorwide (for sector-specific factors) rate of return. Due to its vintage structure, equilibrium on the capital market means that there is a common rental rate for new capital (which is perfectly mobile across sectors), old capital in expanding sectors and old capital that is released from declining industries (and also assumed to be perfectly mobile), while old capital in declining sectors earns a return that depends on its productivity in the specific sector.

Third, total investment equals total savings.

\section{Dynamics}

There are three different forces that drive the dynamics of the model. The two exogenous drivers are population and labor growth, and productivity increases, while the vintage capital structure is an endogenous driver.

To reflect population and labor force growth, the estimates of the United Nations Population Division ${ }^{9}$ are incorporated into the model. Hereby, the working force is defined as the population between age 15 and 65 .

Also productivity increases are built-in exogenously. Technological progress is assumed to be factor neutral in the agricultural sector, and labor-augmenting in the other sectors.

Finally, the vintage capital structure (see Section 1 above) drives the model's dynamics. This is inherently an endogenous process as new capital investments and thus the existing capital structure at any given point in time are resulting from decisions taken by optimizing agents.

\section{References to Appendix A}

Banse, M., van Meijl, H., Tabeau, A., \& Woltjer, G. (2008). Will EU biofuel policies affect global agricultural markets? European Review of Agricultural Economics , 35 (2): 117-141.

Birur, D. K., Hertel, T. W., \& Tyner, W. E. (2008). Impact of biofuel production on world agricultural markets: a computable general equilibrium analysis. GTAP Working Paper No. 53.

Huang, J., can Tongeren, F., Dewbre, J., \& van Meijl, H. (2004). A new representation of agricultural production technology in GTAP. Presented at the 7th Annual Conference on Global Economic Analysis, Washington DC, USA .

\footnotetext{
${ }^{9}$ For details and documentation on these estimates see http://www.un.org/esa/population/.
} 


\section{Appendix B. Developing Database to Accommodate Land-use and Biofuels Modules in to the Global CGE model}

\section{Background}

The model uses GTAP database developed at Purdue University (Indiana, USA) under the Global Trade Analysis Project (GTAP). The latest version (Version 7) of GTAP database, provides data for year 2004 on international trade (bilateral flows as well as trade barriers), production, final consumption and consumption of goods and services, for 112 countries/regions and 57 sectors. The GTAP database, however, does not have information on biofuel sectors. For introducing the new sectors into the GTAP database we use the software Splitcom (Horridge, 2008).

In 2004, the major feedstock crops used for producing biofuels were corn and sugar (together representing almost $85 \%$ of the total biofuel production in value), while wheat, rapeseed oil, soybeans and palm oil were also used.

In GTAP, sugar is mapped to the "Sugar cane, sugar beet" sector, corn belongs to the "Cereal grains" sector, wheat is by itself in the "wheat" sector, rapeseed oil and soybean are part of the "Oil seeds" sector, and palm oil is included into the "Vegetable oils and fats" sector. We split 'cereal grain' sector and commodity to generate corn sector and commodity. The remaining "Cereal Grains" sector includes other cereals such as barley, rye, oats, buckwheat, canary seeds, millet and others. Although rapeseed oil, soybean and palm oil are mixed with other oils unused for producing biodiesel, we did not split them out from their original GTAP sectors. This is because, rapeseed oil and soybean are the main components of the "Oil seeds" sector, and they can easily be distinguished from each other as they are specific to certain regions: rapeseed oil being used to produce biodiesel in Europe while soybean is used mainly for producing biodiesel in the US. Moreover, in 2004, palm oil remained a marginal feedstock to produce biodiesel. Similarly, ethanol can be produced from either sugar cane or sugar beet, but it is not paramount to separate "Sugar cane" from "Sugar beet" as it can be easily differentiated between ethanol production systems. "Sugar cane" is the main sugar crops used for producing ethanol and it is mainly used in Brazil and a few other Latin American countries as well as some African and Asian countries, whereas "Sugar beet" is relatively marginal and transformed into ethanol only in Europe.

Biofuels replace part of the conventional transport fuels with which they are directly in competition. Ethanol and biodiesel competes with gasoline and biodiesel, respectively. In the GTAP database the "Petroleum and coal products" sector is the sole sector for transport fuels. Detailing further the production side of the CGE model (see Figure A3 in Appendix A) separating gasoline and biodiesel from the other petroleum products is required. We split the "Petroleum and coal products" sector into gasoline, diesel and other oils.

We created four biofuel sectors: three bioethanol sector and one biodiesel sector. The three ethanol sectors introduced are corn-based ethanol, ethanol based on cereals other than corn (including wheat and other cereal grains), and sugar-based ethanol. The fourth biofuel sector is for biodiesel produced from oilseeds, soybeans or palm oil. We consider the possibility of multiple feedstocks for a biofuel to capture the reality. For example, in 2004, Canada produced ethanol from corn as well as from grains (wheat and other cereal grains), Germany produced ethanol from grains and sugar beet but also made biodiesel from rapeseed oils.

\section{Methodology}

The biggest challenge when modifying data of a SAM is to maintain it balanced. For each account of the SAM, the sum of the columns should strictly equal to the sum of the rows. The Splitcom software is designed to split existing sectors of the GTAP database ensuring that the balance of the 
SAM is maintained. Using Splitcom, a new sector can only be introduced into the GTAP database from an existing one. Moreover, only one existing sector can be split at a time. As mentioned earlier, we generated corn, gasoline and diesel from the existing GTAP sectors.

Following Taheripour et al. (2008) we split the "Food products" sector to create sectors of ethanol from grains (corn and other grains). We also generate the biodiesel sector from the "Food products" sector. While Taheripour et al. (2008) split the "Chemical, rubber, plastic products" sector to add the sugar-based ethanol sector, Valin et al. (2009) also split the "Chemical, rubber, plastic products" sector but only in the case of Brazil. As compared to Taheripour et al. (2008), Valin et al. (2009) do not only consider production of sugar-based ethanol in Brazil but also in countries such as India, Pakistan and from the Central America region. For these countries, they split the "Sugar" sector, leading to the creation of a total of two ethanol sectors from sugar crops. After carefully reviewing GTAP data of "Chemical, rubber, plastic products" and "Sugar" sectors as well as ethanol data for the different GTAP countries/regions we also opt for the creation of two sugar-based ethanol sectors as suggested by Valin et al. (2009). Production costs of ethanol from sugar are different for Brazil and the other producers (especially European countries producing ethanol from sugar beet whereas Brazil is producing ethanol from sugar cane) and while the large "Chemical, rubber, plastic products" sector can comfortably be utilized for creation of sugar-based ethanol for Brazil, the GTAP input-output tables of other producers suggest the use of another sector to limit distortions within the "Chemical, rubber, plastic products" sector. On the other hand, the "Sugar" sector of moderate size could not accommodate the creation of sugar-based ethanol sector for Brazil as Brazilian's production in 2004 is already quite significant. Finally, we split the "Chemical, rubber, plastic products" sector for the creation of sugar ethanol for Brazil and we split the "Sugar" sector to introduce the sugar ethanol sectors for other GTAP countries/regions. The two sugar ethanol sectors are then aggregated to a single sugar-based ethanol sector.

\section{Data \\ Corn sector}

Production block: For splitting corn from other cereal grains we collect 2004 production data $^{10}$ in tons from FAO for 229 countries and eight commodities: corn, barley, rye, oats, buckwheat, canary seeds, millet and other cereals not elsewhere specified. Data being expressed in tons, we convert these volumes into USD values using the 2004 producer prices ${ }^{11}$ obtained from FAO. When necessary, we use an official exchange ${ }^{12}$ rate from the World Bank. We compute percent shares of the total production of cereal grains for corn and for other cereal grains. Although corn is the dominant type of cereal grains produced by more than half of the GTAP regions it is not the case for many European, Middle East and North Africa, and some Sub-Saharan African countries ${ }^{13}$.

Trade: The bilateral trade data ${ }^{14}$ are taken from the United Nations Commodity Trade Statistics Database (COMTRADE) to split the other cereal grain sector. We the 4-digit codes of the Harmonized System to identify the different components of the cereal grain sectors. After the split, the data which were available for 229 countries, aggregated over the 112 GTAP countries/regions

${ }^{10}$ FAO ProdSTAT available at: http:// faostat.fao.org/site/567/default.aspx\#ancor.

${ }^{11}$ FAO PriceSTAT available at: http://faostat.fao.org/site/570/default.aspx\#ancor.

${ }^{12}$ World Development Indicators (WDI - Sept. 2008). Data can be found on the Development Data Platform (DDP)) of the World Bank.

${ }_{13}$ Barley is the dominant cereal grain produced by Middle East, North Africa and developed Asia whereas millet and sorghum are paramount in some African economies.

${ }^{14}$ Data can be downloaded from the World Integrated Trade Solution (WITS) of the World Bank. 
and their respective shares in the total cereal grains computed.

Consumption: The consumption data for corn is obtained through the commodity balance equation (i.e., production plus imports minus exports). Total consumption corresponds to the sum of the intermediate, household, and government consumptions and stock change. We further divided the total consumption between consumption of domestic production (or production minus exports) and consumption of imports. For getting the total imports and total exports of a country we simply sum up bilateral trade over exporters and importers, respectively.

\section{Gasoline and diesel sectors}

We split the "Petroleum and coal products" into gasoline, diesel and other oils sectors using the information on production, trade and consumption of gasoline, diesel and other oils taken from the 2009 World Energy Statistics and Balances prepared by the International Energy Agency ${ }^{15}$.

Production: IEA data are aggregated for the GTAP regions and shares of gasoline, diesel and other oils in the total petroleum are computed for each GTAP region.

Trade data: We use total exports and imports of gasoline, diesel and other oils by country can be sufficient for our purpose. To create bilateral trade of these commodities we used the same proportions as it is for the "Petroleum and coal products" in the original GTAP database. This would however, does not provide precise bilateral trade information for gasoline, diesel and other oils, but we did not have any better alternative.

Consumption: The IEA database provides information on consumption of gasoline, diesel and other oils by major industrial sectors as well as households. All gasoline in the road transport sector of IEA is allocated to household sector of GTAP ${ }^{16}$. Part of diesel used for road transportation is, in fact, used by cars and small trucks owned by households, but we did not have any technique to estimate by how much. So the implicit assumption here is that all diesel used for road transportation is used for public transport. However, this is does not influence the results as most of diesel is used for public transportation in most countries.

\section{Biofuel sectors}

Ethanol production: As opposed to corn, gasoline and diesel sectors, biofuel sectors do not have any clear correspondences in the GTAP sectors. Production data for ethanol sectors come from F.O. Litch, cited by the Renewable Fuels Association (2005) ${ }^{17}$. We use the US average price for the year 2004, to convert data into millions USD ${ }^{18}$. Ethanol can be produced from different feedstocks in several countries; feedstock shares are obtained from Biofuel CropLife ${ }^{19}{ }^{20}$ European Bioethnaol Fuel Associations (eBio) ${ }^{21}$ and Ogha and Koizumi (2007). Production cost structures are derived based on information from Smeets et al. (2005) for corn, wheat sugar beet for all countries and sugarcane in Brazil. For sugarcane produced elsewhere we use Yoosin and Sorapipatana (2007).

\footnotetext{
${ }^{15}$ Data can be found at: http://puck.sourceoecd.org.libproxywb.imf.org/vl=3417019/cl=13/nw=1/rpsv/statistic/s35 about.htm?jnlissn=16834240

${ }^{16}$ IEA transport sector includes all energy used for transportation no matter the vehicles are owned by households or industries. Therefore, special care should taken while mapping the IEA sectors with that of GTAP sectors.

${ }^{17}$ Data available at the following Internet address: http://www.ethanolrfa.org/pages/statistics.

${ }^{18} 1$ gallon is equal to 1.69 USD; Nebraska government website: http://www.neo.ne.gov/statshtml/66.html.

${ }^{19} \mathrm{~A}$ few countries in Asia as well as in Africa use in fact molasses instead of sugar cane to product ethanol from sugar. Yet, since molasses as feedstock cannot be easily identified into the GTAP database, and that molasses is obtained from sugar cane, we decided to assign a production of sugar cane to the countries producer of molasses.

${ }^{20}$ Information can be found at: http://biofuels.croplife.org/index.php?page=regions.

21 All the details are given by the Ensus Group (2008) and are available at: http://www.biofuelwatch.org.uk/files/ensus factsheet.pdf.
} 
Biodiesel production: Biodiesel production data come from various sources: the European Biodiesel Board $(\mathrm{EBB})^{22}$ for the European economies, The National Biodiesel Board $(\mathrm{NBB})^{23}$ for the United States. For Malaysia and Indonesia, we got crude Palm Oil production data for year 2004 from the Oil World (2008). Following Ogha and Koizumi (2007), we estimated the production of palm oil biodiesel in both countries ${ }^{24}$. For biodiesel production cost structure, we used information from Smeets et al. (2005) for biodiesel from rapeseed oil and soybeans. In the case of biodiesel from palm oil, we used Japan Petroleum Energy Center (2004) cited in Ohga and Koizumi (2007).

Ethanol trade: For ethanol trade, we use data classified under the Harmonized System nomenclature at the four-digit level (HS4). The corresponding product is "Undenatured ethyl alcohol of an alcoholic strength by volume 10 of $80 \%$ vol or higher; ethyl alcohol and other spirits, denatured, of any strength" which has for HS4 code $2207^{25}$. As we are creating several ethanol sectors depending on the feedstocks used to produce ethanol we need to distribute total bilateral trade of ethanol within the different feedstock-based ethanol. Therefore, we apply the previously computed shares of production by feedstock to split the trade data.

Biodiesel trade: Regarding biodiesel produced from rapeseed oil, we get the total imports and exports data by country from the International Energy Agency (IEA). For bilateral trade of biodiesel, we utilize the structure of bilateral trade given by COMTRADE data for the HS6 code 382490. Moreover, bilateral trade data for biodiesel made of palm oil are directly available from the Malaysian Palm Oil Board (MPOB) ${ }^{26}$.

\section{Consumption data}

It is important to note that for countries/regions not producing biofuels in 2004, tiny nonzero numbers are added in the split process of all biofuel data. This avoids eliminating biofuel sectors for initially non-producer countries in the CGE model and allows for future biofuel production in those countries. More details about data treatment (especially treatment of missing data) and sector splits (details of each step using Splitcom) can be found in Mevel (2009).

\section{Data on Key Elasticity Parameters}

Most of the elasticity parameters are taken from the literature. Since the results are sensitive to some elasticities, special attention was paid while choosing their values. These are: substitution elasticities between biofuels and competing fossil fuels, land use elasticities, and other substitution elasticities of the production structure of the model.

Elasticities between biofuels and fossil fuels: Biofuels compete directly with fossil fuels in transportation. The results are highly sensitive to elasticity of substitution between biofuels and fossil fuels. Birur et al. (2007) collect historical data allowing them to determine a default value of 2.0 for this elasticity parameter. Yet, they point out the lack of data availability for conducting econometric analysis and they acknowledge that the value could vary significantly across countries (especially if a country is already equipped with flex-fuel vehicles or not). After several sensitivity analyses varying this parameter, we decided to nearly triple its value overtime, between 2004 and 2020, from 1.2 to 3.0 for all countries. We think it is realistic with future expansion of flex-fuel

\footnotetext{
22 Data can be accessed from the following link: http://www.ebb-eu.org/stats.php.

${ }^{23}$ More details can be found at: http://www.biodiesel.org/.

24 In 2004, Malaysia and Indonesia do not yet officially produce biodiesel, although they already have capacities and equipments. Nevertheless, in the next years their biodiesel production took off drastically and therefore we consider a small production for both economies from 2004, based on 2006 assumptions.

${ }^{25}$ Data available for download from the World Integrated Trade Solution (WITS) of the World Bank.

${ }^{26}$ Data available from: http://econ.mpob.gov.my/economy/EID web.htm.
} 
vehicles and we prefer not to consider higher values as they would tend to accelerate biofuel penetration too rapidly.

Land elasticities: In our CGE model, we split total land into 18 Agro-Ecological Zones (AEZs) depending on climate type and humidity levels of the land (Hertel et al. 2009). We use a CES functional form with a high value of 20 for substitution elasticity between AEZs. For a given AEZ, the land supply is constrained across the different land-specific uses with nested constant elasticity of transformation (CET) functional forms. As explained in Appendix A1 above we opted for three nested CET functions with increasingly negative substitution within the levels. An econometric analysis from Choi (2004) suggests transformation elasticities at each level, for the United States, being equal to respectively: $-0.25,-0.5$ and -1.0 for a relatively similar nest structure ${ }^{27}$. Lubowski et al. (2005) indicate a value of -0.11 for the first level of the nest whereas Ahmed et al. (2008) suggest a value of -0.22. Following Hertel et al. (2008) we select an intermediate value of -0.2 for the first level of the structure but consider the same values as Choi (2004) with respectively -0.5 and -1 for the next second levels. We apply the same elasticities for all countries.

Other Elasticities: As shown in Figures A1-A3 in Appendix A, all functional forms used in the nested structure are CES. At the top (i.e., aggregation of intermediate demand and value added), the elasticity of substitution is zero thereby assuming Leontief production function. The rest of the production structure is represented by CES functions ${ }^{28}$ with increasing substitution elasticities between the different levels. Values for substitution elasticities are taken from Burniaux and Chateau, OECD (2010); van der Werf (2008); Timilsina and Shrestha (2006); Ma et al (2010); Jarrett and Torres (1987) and Narayanan and Walmsley (2008). The elasticities differ across the capital vintage, lower for old vintage and higher for the new.

\section{References of Appendix B}

Ahmed A., Hertel T., and R. Lubowski R., "Calibration of a Land Cover Supply Function Using Transition Probabilities”. GTAP Research Memorandum No 14. Center for Global Trade Analysis, Purdue University, West Lafayette, IN, USA, 2008

Birur, D., Hertel T., and Tyner W., "Impact of Biofuel Production on World Agricultural Markets: A Computable General Equilibrium Analysis.” GTAP Working Paper No. 53, presented earlier at the 10th Annual Conference on Global Economic Analysis, Purdue University, West Lafayette, IN, USA, 2007

Burniaux J-M. and Chateau J.,"Background Report: An Overview of the OECD ENV-Linkages model", OECD, May 2010

Choi S., "The Potential and Cost of Carbon Sequestration in Agricultural Soil: An Empirical Study with a Dynamic Model for the Midwestern U.S." Ph.D. Thesis, Department of Agricultural, Environmental, and Development Economics, Ohio State University, 2004

Ensus Group, "How a venture capitalist firm is helping to push up the price of food?", 2008

Hertel T., Tyner W., and Birur D. "Biofuels for all? Understanding the Global Impacts of Multinational Mandates", Center for Global Trade Analysis, Department of Agricultural Economics, Purdue University, REVISED November 2008, GTAP Working Paper No. 51,

\footnotetext{
${ }^{27}$ In the work undertaken by Choi (2004): -0.25 is the elasticity of transformation between agriculture and forest lands, -0.5 is the elasticity of transformation between crops and livestock, and -1.0 is the elasticity of transformation between crops.

${ }^{28}$ Note that we have CET functions for the land use structure as already explained in the previous section.
} 
2008

Hertel T., Rose S., and Tol R., "Economic Analysis of Land Use in Global Climate Change Policy", Routledge, April 2009

Horridge M., "SplitCom: Programs to disaggregate a GTAP sector", Centre of Policy Studies, Monash University, Melbourne, Australia, November 2005 (revised Jan 2008)

Jarrett P. and Torres R., "A revised supply block for the major seven countries in INTERLINK", OECD Department of Economics and Statistics Working Papers No. 41, April 1987

Lubowski R., Plantinga A., and Stavins R.,"Land-Use Change and Carbon Sinks: Econometric Estimation of the Carbon Sequestration Supply Function", Regulatory Policy Program Working Paper RPP-2005-01. Cambridge, MA: Center for Business and Government, John F. Kennedy School of Government, Harvard University, 2005

Ma H., Oxley L., and Gibson J., "China's energy economy: A survey of the literature", Economic Systems, Elsevier, vol. 34(2), pages 105-132, June 2010

Narayanan, B.G. and T. L. Walmsley, Editors (2008). Global Trade, Assistance, and Production: The GTAP 7 Data Base, Center for Global Trade Analysis, Purdue University.

Ohga K., and Koisumi T, "Biofuels Policies in Asia: Trade effects on World Agriculture and Biofuels Trade", USDA Agricultural Outlook Forum, March 2, 2007

Oil World, "Statistics Update”, ISTA Miekle GmbH, Hamburg, March 14, pp. 15-68, 2008

Renewable Fuels Association, "Homegrown for Homeland: Industry Outlook 2005", Washington, DC, 2005

Smeets E., Junginger M., and Faaij A., "Supportive study for the OECD on alternative developments in biofuel production across the world", Report NWS-E-2005-141, ISBN 908672-002-1, December 2005

Taheripour F., Birur D., Hertel T., and Tyner W., "Introducing Liquid Biofuels into the GTAP Data Base", GTAP Research Memorandum No.11, 2007, Revised May 1, 2008

Timilsina G. and Shrestha R., "General equilibrium effects of a supply side GHG mitigation option under the clean development mechanism", Journal of Environmental Management 80, p.327-341, 2006

US Department of Energy, "The Clean Alternative Fuel Prices”, March 23, 2004

US Department of Energy, "The Clean Alternative Fuel Prices”, June 29, 2004

US Department of Energy, "The Clean Alternative Fuel Prices", November 26, 2004

Valin H., Dimaranan B., and Bouët A., "Biofuels in the world markets: A Computable General Equilibrium assessment of environmental costs related to land use changes", Presented at the 12th Annual Conference on Global Economic Analysis, Santiago, Chile, November 2009

Van der Werf E., "Production functions for climate policy modeling: An empirical analysis. Energy Economics, 30, 2964-2979, 2008

Yoosin S. and Sorapipatana C., "A study of Ethanol Production Cost for Gasoline Subtitution in Thailand and Its Competitivness", Thammasat Int. J. Sc. Tech., Vol. 12, No. I, January-March 2007. 